ECONOMIC GROWTH CENTER

YALE UNIVERSITY

P.O. Box 208629

New Haven, CT 06520-8269

http://www.econ.yale.edu/ egcenter/

CENTER DISCUSSION PAPER NO. 895

\title{
MOTIVES FOR HOUSEHOLD PRIVATE TRANSFERS \\ IN BURKINA FASO
}

\author{
Harounan Kazianga \\ Yale University \\ and \\ Columbia University
}

October 2004

Notes: Center Discussion Papers are preliminary materials circulated to stimulate discussions and critical comments.

Technical and financial support from the Economic Growth Center, Yale University and the Rockefeller Foundation Grant for Postdoctoral Research on the Economics of the Family in Low Income Countries is gratefully acknowledged. I have benefitted from very helpful comments by Joe Altonji, T. Paul Schultz, Rodney Smith, Chris Udry, participants of the Development Lunch at Yale University, and from two anonymous referees. I thank the Burkinabe Institut National de la Statistique et de la Demographie for the data. All remaining errors are mine.

This paper can be downloaded without charge from the Social Science Research Network electronic library at: $\underline{\text { http://ssrn.com/abstract }=607664}$

An index to papers in the Economic Growth Center Discussion Paper Series is located at: http://www.econ.yale.edu/ egcenter/research.htm 


\title{
Motives for Household Private Transfers in Burkina Faso
}

by

\section{Harounan Kazianga}

\begin{abstract}
Resource transfers among households have received considerable interest among economists in recent years. Two of the main reasons for the surge of interest in household transfers are the information on human nature conveyed by transfer behavior and the implication on income redistribution policy that private transfer might have. Empirical studies, however, provide mixed results on transfer behavior. This is because previous inquiries were confronted with several estimation issues and have focused on data from developed countries where private transfers are already small. This paper contributes to the literature on transfer behavior by using a multifaceted econometric approach to examine the motives of household transfers in Burkina, a low-income country with a well-documented tradition of gift exchanges. The findings suggest that risk sharing is not central to transfers. Altruistic transfers are apparent for the middle income class, but not a low income level. The evidence implies that crowding out may be minimal at a low income level, suggesting that public transfers targeting poor households may be effective.
\end{abstract}

Keywords: Private transfers, Altruism, Exchanges, Risk Sharing

JEL classification: D63, D64, I15, I30 


\section{Introduction}

Following the pioneering work of Becker (1974) and Cox (1987), economists have paid growing attention to the importance and the motives of private transfers among households ${ }^{1}$. Three main theoretical hypotheses have been advanced to explain such transfers. First, according to the altruistic model, donors care for the well-being of recipients, and transfers depend on the financial situation of both the donor and the recipient(Becker, 1974). Second, under exchange motive, transfers are rooted in a reciprocity structure, and they may be seen as the counterpart of previous transfers (Cox, 1987; Foster and Rosenzweig, 2001). Third, under mutual insurance, households enter into mutual agreements, and transfers of transitory income are used to smooth consumption (e.g. Townsend, 1994). In addition to conveying useful information on human behavior, knowing the underlying motive of these transfers has strong policy implications on the effectiveness of public transfers $^{2}$. The main policy concern is that compensatory reductions in private transfers, if large enough, may effectively neutralize the effects of public transfers (Barro, 1974; Becker, 1974).

This paper explores the motives for inter-household private transfers in Burkina Faso, a lowincome country in the Sahel region of West Africa ${ }^{3}$. Arguably, Burkina offers an interesting setting for examining transfer response to income. Formal transfers are very limited, and private transfers are believed to be important. About 90 percent of the population lives in rural areas, and virtually all rural population depends on rainfed agriculture as the basis for their livelihoods. Presumably, rainfall variability in conjunction with very low income levels create a pressing need for insurance, which in absence of formal markets is met with informal arrangements ${ }^{4}$. Gift exchanges are believed to be a central element of these social arrangements (e.g. Shipton, 1990). The central role occupied by gift exchanges in Burkina is well documented through anthropological and sociological literature (e.g. Fiske, 1990; Hammond, 1966; Saul, 1981, 1983). This strand of work portrays a complex gift exchange system which involves relatives and friends, and encompasses what may be viewed as exchange, altruistic, and insurance motivated transfers ${ }^{5}$. Furthermore, social norms prescribe the

\footnotetext{
${ }^{1}$ See Varet-Gerard, Kolm, and Ythier (2000) for a recent review.

${ }^{2}$ For example, while public transfers are crowded out by altruistically motivated transfers, Cox and Jakubson (1995) found that an extent of public transfers may increase the amount of financial transfers received under exchange. Ignoring risk sharing pattern within the kinship network has dampened the effectiveness of a response to famine in southern Sudan (Harragin, 2004).

${ }^{3}$ For example, income per capita per year is estimated at $\$ 220$ (or $\$ 0.60$ a day, far below the conventional measure of $\$ 1$ a day adopted for global poverty measure), life expectancy at birth is estimated at 42.9 years, and under five mortality is estimated a 207 per 1000. See http://www.worldbank.org/afr/bf for more details.

${ }^{4}$ For a characterization of rainfall variability in the region, see Nicholson and Paolo (1993).

[Hammond (1966, p. 99-100)'s illustration of gift exchanges between two brothers gives a flavor of the flow and the widespread of transfers in the region.
}

"When a Moose man gives several bundles of millet to his younger brother whose harvest were damaged by an invasion of migratory locusts, he does not expect and perhaps will not receive a return gift of an equal amount of grain.

But he has a right to expect, and will receive something, or some things of approximately equal valuea goat, help in repairing the roof of his granary, perhaps over a period of several months a variety of 
provision of support to the elderly (e.g. Badini, 2004) and to the less fortunate kinship members (e.g. Riesman, 1974), which in practice leads to altruistic transfers ${ }^{6}$. In earlier data collection efforts, Ancey (1983) found that for 22 percent of migrants the most important fraction of migration costs were paid by transfers from relatives, suggesting that transfers may help overcome borrowing constraints. Data from recent national surveys reported in table 1 support that transfers are frequent in Burkina ${ }^{7}$. About 39 percent of rural households surveyed in 1994 and 42 percent of those surveyed in 1998 report some transfer activity, either as donor, recipient, or both. About 40 percent and 43 percent of urban households were involved in some transfer activity in the same periods, indicating that transfers are not limited to rural areas. Transfers contributed on average to 36 percent and to 19 percent in rural recipient households income in 1994 and 1998, respectively, and to 15 percent and 16 percent in urban recipient households in 1994 and 1998, respectively. Most rural households were recipient only: 26.3 percent received transfers in 1994 and 28 percent in 1998, while most urban households were donors only, 22 percent and 21 percent in 1994 and 1998. This suggests that eventual interactions between private and public transfers might impact the welfare of a large fraction of the population. This observation is reenforced by the renewed interest in the provision of social protection and formal risk management mechanisms to low income households (e.g. Ravallion, 2003) ${ }^{8}$.

The empirical evidence on both the existence and the magnitude of transfer response to income is, however, mixed. A number of studies (e.g. Cox and Jakubson, 1995; Cox and Rank, 1992, Altonji, Hayashi, and Kotlikoff, 1997) have found a significant but small effect of public transfers on private ones. In contrast, other studies (e.g. Cox and Jimenez, 1992, 1995; Cox, Hansen, and Jimenez, 2004) found a substantial effect of the displacement of private transfers by public ones. Furthermore, empirical results from developed countries may be of little relevance for policy guidance in low-income countries, partly because the settings differ and partly because the research focus in developed countries is dominated by inter-generational transfers (inter-vivos or bequests) while intra-generational transfers are equally important in low-income countries. There are four possible explanations to the weak transfer response uncovered in numerous empirical studies. First,

several small presents in the form of goods and services which add up to an equivalent value. In practice before he has received an equal amount in return, he may ask his young brother for some maize, which at this point in their transactions reverse the obligation. The next gift should move the other way (...) All the Moose men, women and children participate in this system and are usually involved in several such reciprocal relations at any time(...) The object is not to close such transactions, but to keep them going."

\footnotetext{
${ }^{6}$ If these social norms are actually enforced and even if the donor does not care for the economic well-being of the recipient (as assumed by the altruistic model), the transfer pattern will be observationally equivalent to that implied by altruistic models.

${ }^{7}$ These surveys are the first and second Priority Surveys conducted by the Institut National de la Statistique et de la Demographie.

${ }^{8}$ For discussion on social protection programs in Africa, see World Bank (2001). For the specific case of Burkina, see World Bank (2004). For a more comprehensive coverage of the World Bank interventions in social protection in low-income countries, see http://www1.worldbank.org/sp.
} 
analysis using data from developed countries is less likely to find significant crowding-out effect, because public transfers have already reduced private ones (Cox, Hansen, and Jimenez, 2004). Second, the response of private transfers might differ depending on the type of public interventions. For instance, Cox and Jimenez (1995) estimate that an unemployment insurance system would have a strong crowding-out effect in the Philippines, while the degree of crowding-out associated with pensions is much less significant. Since pension is likely to be permanent and unemployment insurance is more transitory, a possible interpretation of Cox and Jimenez's finding is that transfer response to permanent and to transitory income differs. This point has received little attention in the transfer literature. Third, it is possible that transfers be motivated by altruism when recipient income is low, and then exchange motives become determinant when the recipient income reaches a certain threshold (Cox, Hansen, and Jimenez, 2004). Such a transfer behavior generates nonlinearities in the response function, which if not properly controlled may bias the estimates. Finally, and in addition to these concerns, there are the long standing issues associated with selection into transfer transactions and income endogeneity. This line of reasoning suggests that tests for transfer response to income must focus on areas where private transfers are (or believed to be) important and must address the related estimation issues.

This paper makes two contributions to the existing literature on transfer behavior. The first contribution lies in the focus on Burkina, a region where gift exchanges are important according to anthropological and sociological work, but where transfer behavior has received relatively little attention from economists. The second contribution, presumably the more important, is the attempt to address a range of estimation issues including self selection into transfers transactions, income endogeneity, and non-linearities of the transfer response function, which may have substantially influenced the conclusions drawn from previous studies. While these issues have been addressed separately in different studies, it is conceivable that grappling with them using a unique dataset could shed new insights on the transfer response to income. Finally, by adapting income instrumenting techniques used in the risk-sharing literature, the study is able to disentangle the influence of permanent and transitory income on transfers received, an issue which has been only implicit in previous studies.

The main findings can be summarized as follows. While it is apparent from the descriptive analysis that private transfers reduce income inequality, the econometric analysis points to a relatively small transfer response to income. In addition, transfer reaction to income is relatively smaller at the lowest income level compared to the medium income level, contrasting with recent findings by Cox, Hansen, and Jimenez in the Philippines who find relatively larger transfer response at low income level. This suggests that in the context of Burkina, crowding out effects may not be an issue for very low income level, implying that public transfers targeting the poorest households could be effective. There is also evidence of weak transfer response to transitory income suggesting that insurance role in transfers is minimal. It is also apparent that ignoring the non-linearity 
in the transfer-income relationship and income endogeneity with respect to transfers may lead to misleading estimated transfer response to income.

The findings provide some insights into human nature and the underlying motivations for private transfers, although the results are far from conclusive. For example, the lack of transfer response to income at very low income level combined with the relatively strong response at medium income level suggests that there may be a threshold below which changes in income do not affect transfer, a pattern which contrast with both altruistic and exchange transfer motives as described in the literature. It is also apparent that risk sharing motivated transfers are observed only for relatively large income shocks, a pattern which is consistent if only large income shocks are easily observable. This may reflect a seasonal pattern of transfers, where poor people transfer out immediately after harvest while rich people transfer out later during the slack season, is more consistent with reciprocal gift exchanges described by the anthropological literature.

The remainder of the paper proceeds as follows. The second section presents the analytical framework. The third section discusses the data. The fourth section discusses the empirical strategies. The fifth section presents the estimation results, and the sixth section concludes.

\section{Theoretical framework}

The analytical framework developed by Cox (1987) is used to motivate transfer functions, which relates transfers received to the recipient income. The model generates two predictions on the relationship between the recipient income and the amount of transfers received. On the one hand, if transfers are altruistically motivated, then transfers received should decrease as the recipient income increases. On the other hand, transfers received will decrease as recipient income rises if exchanges were the underlying motive. Moreover, under certain circumstances, the model allows transfers to rise with recipient income.

Formally, assume that there are two individuals, the donor denoted $d$ and the recipient denoted $r$. The amount of transfer is $T$, and the recipient provides some services $S$ to the donor, which by assumption do not have market substitute. Furthermore, I assume a one-sided altruism from the donor. The donor utility $U$ is increasing in his consumption of an aggregate good $C_{d}$, the amount of services consumed $S$ and the recipient utility $V$. The last relationship captures altruism in the model. The recipient utility $V$ is increasing in his consumption $C_{r}$ and decreasing in $S$. The donor solves the following program: 


$$
\begin{aligned}
& U_{d}=\quad U\left(C_{d}, S, V\left(C_{r}, S\right)\right) \\
& C_{d}=\quad I_{d}-T \\
& \begin{array}{ll}
C_{r}= & I_{r}+T
\end{array} \\
& V\left(I_{r}+T, S\right) \geq \quad V_{0}\left(I_{r}, 0\right)
\end{aligned}
$$

Equations (1b) and (1c) represent the budget constraints faced by the donor and the recipient respectively. Equation (1d) is the participation constraint, which states that the recipient entering in the relationship must not lower his utility. Cox (1987) shows that this program generates two regimes, depending on whether the participation constraint is binding or not.

Under the first regime, the participation constraint is not binding $\left(V>V_{0}\right)$. The transfers are then altruistically motivated, and the recipient is more than compensated for his services. The net transfers received decrease with the recipient income. Assuming interior solution, the predicted relationship between transfers and income is $\partial T / \partial I_{d}-\partial T / \partial I_{r}=1$, which is the transfer income derivative tested by Altonji, Hayashi, and Kotlikoff (1997). In other words, conditional upon transfers having been made, a decrease of one unit in the donor income followed by an identical increase in the recipient income, leaves the transfer amount unchanged.

Under the second regime, the participation constraint is binding (for instance, the recipient pre-transfer income is high enough), the transfers are motivated by exchanges, and the recipient is compensated for his services. This regime can be pictured as if transfers were made in order to compensate services $S$ which have an implicit price $P$. Thus the relationship between transfers and services is expressed as: $T=P S$. Cox shows that transfers first increase with income and then fall, thus generating an inverted $U$ shape ${ }^{9}$. Both motives may co-exist in the same dataset, occurring at different income levels, thereby inducing non-linearities of the transfer response.

In the empirical work, permanent and transitory incomes will enter the transfers function separately. This specification is then used to explore the role of transfers in risk sharing. From the risk-sharing model (Cochrane, 1991; Townsend, 1994), if the sole purpose of transfers were coping with unpredicted income shocks, then only transitory income affects transfers, and permanent

${ }^{9}$ More formally, the argument proceeds as follows:

$$
\frac{\partial T}{\partial I_{r}}=\frac{\partial S}{\partial I_{r}} P+\frac{\partial P}{\partial I_{r}} S
$$

The first term of the right-hand side is negative and the second term positive. Thus, the overall effect depends on whether the price or the quantity effect dominates. Cox shows that the price effect will initially dominate, and then the quantity effect dominates as the recipient decreases the quantity of services at certain pre-transfer income levels. Thus, the transfers first increase with income and then fall. One should note the argument that this pattern is consistent with exchange-motivated transfers but does not constitute a proof of exchange-motivated transfers, since other behavior may generate similar empirical patterns. For instance, see Lucas and Stark (1985) for the relationship between remittances and home household income in Botswana. 
income should not be a significant determinant of transfers 10 .

\section{$3 \quad$ Data and Descriptive statistics}

The paper uses the two rounds of the national priority surveys conducted in 1994 and in 1998 . The two surveys are similar in the scope of the information collected, the sampling design, and the coverage. The surveys are closely related to the World Bank LSMS, and are intended to be nationally representative; the sample selection uses a two-stage stratified random sampling. The number of households interviewed was 8700 in 1994 and 8478 in 1998.

The surveys collected information on household and individual characteristics, employment status, expenditures, and income. Information on transfers was collected at the household level. Transfers given were collected along the consumption module with a recall period covering the month preceding the survey, while transfers received were collected along with the income module with a recall period covering the previous twelve months. Two issues are related to these differences in the recall periods. First, if seasonal variations are important, then transfers given are more likely to be misreported. Second, if intra-annual inflation is important, then nominal values of transfers given and received might reflect, in fact, different real values (Paxson, 1992).

Annual transfers given are obtained by multiplying monthly values by 12 . This procedure is not valid if there is a strong seasonal pattern in transfers so that the probability that a respondent reports non-zero transfer varies with the survey month. In table 2, I report both the frequency of non-zero transfers given and transfer size for each month. It is apparent from table 2 that the frequency of transfer flow is stable across the two years. In each year, approximately 15 percent of the surveyed rural households report positive transfers given, although the 1994 survey had been conducted between October and January, and the 1998 survey between May and July. Approximately 28 percent in 1994 and 27 percent in 1998 of urban households reported positive transfers given out. In columns (3) and (4), I report the unconditional mean of transfer size and a t-test whether there is a significant difference between the average mean in a given month and that of the remaining months. Although in 1998 one cannot reject that mean transfers are equal across survey months, in 1994 mean transfers reported in November and December were different from those reported in January and in October, for both the urban and the rural samples. A potential explanation of these differences is that harvest occurs in November and December, and most in kind transfers are given during this period (e.g. Ellsworth and Shapiro, 1989). This interpretation does not explain, however, why transfers given in January are larger than those given in December. Since there is no clear pattern in these differences, I will attribute them to sampling errors and include month dummies in all the regressions to control systematic changes which may be associated with

\footnotetext{
${ }^{10}$ This hypothesis can be understood through the risk-sharing literature. In the formal risk-sharing model (Townsend, 1994, Cochrane, 1991; Mace, 1991), changes in income, and not permanent income, are redistributed to smooth individual consumption within the insurance group.
} 
the survey period.

- Insert tables [3, 4] and 5 about here.

Descriptive statistics are reported in tables 3,4 and 5, and a summary of all the variables used in the analysis is presented in tables 13 and 14 in the appendix. Tables 3 and 4 report private transfers expressed in local currency units (CFA Franc) per adult in rural and urban areas, respectively. Pretransfer income is income per adult before transfers, and post-transfer income includes net transfers received ${ }^{11}$. In both rural and urban areas, in 1994 and 1998, recipients had the lowest pre-transfer average income per adult. It can bee seen that transfers reduce the income gap between recipient households and the autarkic group. For rural households in 1994, the income ranking between the two groups even reverts after transfers have been accounted for. Next, the sample is split by wealth quartile, using non-durable expenditures per adult as a wealth indicator. Net transfers were positive but decreasing in magnitude as one moves from the first to the third quartile (the first to the second quartile in 1998 for urban households). For the highest income quartile (the high two quartiles for urban households in 1998), net transfers were negative. This suggests that transfers flow from wealthier to poorer households, and thus may have an equalizing effect. Note that, although the absolute numbers differ between the two years, the qualitative pattern is similar, suggesting a rather stable pattern of private transfers over time. Further evidence of the equalizing effects of transfers is provided in table 5 . The table reports pre- and post-transfers income and consumption inequality as measured by Gini and Theil maximum entropy coefficients. The point estimates are reported along with bootstrapped standard errors ${ }^{12}$. In both years, transfers substantially altered welfare distribution, whether expressed in income or in expenditures. Considering income inequality, the Gini coefficient dropped from .571 to .555 in 1994 and from .497 to .474 in 1998 after net transfers were taken into account, in rural areas. In urban areas, the Gini coefficient dropped from .513 to .506 in 1994 and from .489 to .477 in 1998. The Theil inequality measure also indicated a similar pattern. Transfers had an equalizing effect on both income and expenditure distributions. Cox and Jimenez (1995) have reached similar conclusions for the Philippines. These descriptive statistics suggest that the effects of income redistribution policies may be dampened by potential interactions between private and public transfers. It is apparent that if private transfers are responsive to to household income, the net effects of policies seeking to modify income distribution may be reduced.

\section{Empirical strategies}

As discussed in the introduction, transfer response estimate may be too sensitive to estimation methods and to how income enters the regression. The empirical approach followed in this paper consists in using different estimations methods in order to eke out more from the data than one

\footnotetext{
${ }^{11}$ Net transfer is calculated as transfer received minus transfer given.

${ }^{12}$ Bootstrap consisted of 500 replications, correcting for the two-step sampling process.
} 
would learn from a single estimation strategy. I start with a general specification of the transfer function, which follows Altonji, Hayashi, and Kotlikoff (1997) and Altonji and Ichimura (2000):

$$
T=m\left(I_{r}, I_{d}, X, \varepsilon\right)
$$

where $T$ is net transfers received, $I_{r}$ is the recipient income, $I_{d}$ is the donor income, $X$ is a set of controls describing household characteristics that contribute to determine transfer flows. Empirical estimations of (2) are confronted with a number of econometric problems. First, a linear functional form may be a poor approximation of $m$, especially the relationship between transfers and income (see Cox, Hansen, and Jimenez, 2004, for a discussion). Second, unless one imposes strong assumptions, the underlying economic model implies that the error term may not be separable with respect to the other covariates. Third, while both the recipient and the donor incomes enter the transfer function, information is often available only for one transfer partner. The income parameter is estimated with a potential bias if income is correlated between the two transfer partners. Fourth, income may not be exogenously given with respect to transfers so that one needs to instrument for income in order to have consistent estimates. I elaborate more on these issues below.

\subsection{Spline specification}

The first specification follows Cox and Jimenez (1995) and Cox, Hansen, and Jimenez (2004), and uses a spline regression (Greene, 1997), which allows the income parameter to vary over different income quartiles 13 . The spline regression is expressed as follows ${ }^{14}$ :

$$
T_{i}=\sum_{k}^{4} \gamma_{k} I_{i} \cdot I\left(I_{i} \in k\right)+\beta X_{i}+\varepsilon_{i}
$$

Where $T_{i}$ is net transfer received by household $i, k$ indicates pre-transfer income quartiles, $I_{i}$ is household $i$ 's pre-transfer income, $I$ is an index variable which is equal to one for $I_{i}$ falling in quartile $k$ and zero otherwise, and $X$ is a set of variables that affect transfers received.

As is apparent from table 1, more than half of the respondent households neither give nor receive transfers, suggesting that transfers do not adjust smoothly to changes in income. There are both theoretical and econometrical motivations to account explicitly for this large fraction of corner households. Transaction costs associated with transfers, as described by Honore, Kyriazidou, and Udry (1997) or by Udry (1994), would imply that positive transfers are observed only when latent transfers exceed the transaction costs. Alternatively, this pattern may rise if transfers take place within networks, and if there are fixed costs associated with network participation. Regardless of

\footnotetext{
${ }^{13}$ Note that Cox, Hansen, and Jimenez (2004) do not impose the spline's knots a priori.

${ }^{14}$ From here after, I will include only one party's income when writing the transfer function, since there is no information on the other party, including her income. The omitted variable bias resulting from omitting the second party's income is discussed later.
} 
the theoretical explanations, ignoring the presence of the large number of zero values will result in biased inference similar to what occurs with censoring. Following Udry (1994), I use Rosett's friction model (Rosett, 1959) to account for the presence of non-participant households.

$$
T= \begin{cases}T^{*}-\tau_{1} & \text { if } T^{*}<\tau_{1} \\ 0 & \text { if } \tau_{1} \leq T^{*} \leq \tau_{2} \\ T^{*}+\tau_{2} & \text { if } T^{*}>\tau_{2}\end{cases}
$$

where $T^{*}$ is latent net transfer, $\tau_{1}$ and $\tau_{2}$ are unobserved transaction costs, and $T$ denotes the parametric transfer function as defined in $(3)^{15}$. The transaction costs set thresholds that the latent transfers (positive or negative) must exceed in order for one to observe any transfer. This model is estimated by maximum likelihood methods using the likelihood function proposed by Maddala (Maddala, 1983, pages 163-164 ).

\subsection{Altonji and Ichimura estimator}

The specifications above impose that unobservables summarized in the error term enter the transfers function in a separable manner. However, Altonji, Hayashi, and Kotlikoff (1997) show that unless one imposes strong assumptions on the utility function, $X$ and $\epsilon$ are non-separable in the transfer function. It follows that specifications which impose separability between $X$ and $\epsilon$ may be biased, and the direction of the bias is unknown. This motivates a second estimation strategy, which is based on a semi-parametric estimator developed by Altonji and Ichimura (2000). The objective is to recover an estimate of the population average of the marginal effect $E\left[\frac{\partial T^{*}(I)}{\partial I_{i}} \mid I, T>0\right]$ for the self-selected sub-sample with positive transfers. Altonji and Ichimura (2000) and Altonji, Hayashi, and Kotlikoff (1997) show that an estimate of this expression can be obtained as follows:

$$
E\left[\frac{\partial T^{*}(X, \epsilon)}{\partial I_{i}} \mid X, T>0\right]=\frac{\partial \bar{T}(X, \epsilon)}{\partial I_{i}}+\frac{\partial P(T(X, \epsilon)>0 \mid X)}{\partial I_{i}} \cdot \frac{\bar{T}(X, \epsilon)}{P(T>0)}
$$

The A-I estimator is implemented by replacing the right side in (5) with estimates obtained using a global polynomial (in income) approximation to the regression function $E[T(X, \epsilon) \mid X, T>0]$ and the probability function $P\left(T\left(I_{i}, \epsilon\right)>0 \mid X\right)$, where income and other covariates are included in $X^{16}$. Because I have information only for one transfer partner, the left hand side of (5) is evaluated separately for donors and recipients. An approximation of the expression $\partial T / \partial I_{d}-\partial T / \partial I_{r}$ is given as: $E\left[\frac{\partial T^{*}\left(I_{d}\right)}{\partial I_{d}} \mid I_{d}, T>0\right]-E\left[\frac{\partial T^{*}\left(I_{r}\right)}{\partial I_{r}} \mid I_{r}, T>0\right]$

In implementing the A-I estimator, the probability of giving is corrected for the recall period. In particular, I take into account the fact that the probability of giving transfer would have been

\footnotetext{
${ }^{15}$ Recall that by convention, transfers given are negative and transfers received are positive.

${ }^{16}$ I follow Altonji, Hayashi, and Kotlikoff (1997) and use the bootstrap to compute the standard errors.
} 
different if the recall period was the previous twelve months. Suppose that in any given month, the probability of transferring out $p_{m}$, so that the probability of not transferring is $1-p_{m}$. Assuming that the probability of observing non-zero transfer given in any two months is independent 17 :

$$
P_{a}(T>0)=1-\left(1-P_{m}\right)^{12}
$$

\subsection{Semiparametric estimation of the transfer response}

The two estimation strategies presented so far seek to summarize the transfer response into a set of parameters. An alternative is a graphical exploration of the transfer response to income, using a partial linear specification in order to control the effects of the other covariates. The transfer response is specified as follows:

$$
T=g(\operatorname{Ir})+\beta X+\epsilon
$$

where all variables have been defined before. The attractiveness of this specification is that no assumption is imposed on $g$ but smoothness and continuity in $I_{r}$. The main disadvantage is that no parameter is estimated. Examining the general shape of the function may, however, reveal some features of the transfer response function that cannot be summarized easily by a set of parameters. The function $g$ is estimated non-parametrically after partialling out the effects of the other covariates (Robinson, 1988). Compared to specification (2), equation (7) imposes that the transfer function is linear in all other covariates but the recipient income, and the error term is additive ${ }^{18}$.

\subsection{Measure of income}

There are at least three concerns with income, which is the key variable in the transfer function. First, it is well documented that income is measured with errors, especially in developing rural areas where income is derived from various activities that are difficult to evaluate. Second, if households

\footnotetext{
${ }^{17}$ Although the independence assumption seems too strong, it insures simplicity.

${ }^{18}$ The estimation proceeds in two steps as follows. First, the parameter $\beta$ is estimated by estimating separately the nonparametric relationships between $T$ and $I$, and between $X$ and $I$, by forming the residuals, and regressing the residuals of $T$ on those of $X$. Second, the estimated $\hat{\beta}$ is used to estimate the function $g$. The nonparametric estimator used here is the Fan (1992) locally weighted least square estimator with a quartic kernel. The two steps are written as:

$$
\begin{gathered}
\hat{\beta}=\left[\sum_{i=1}^{N}\left(X_{i}-\hat{E}\left[X_{i} \mid I_{i}\right]\right)\left(X_{i}-\hat{E}\left[X_{i} \mid I_{i}\right]\right)^{\prime}\right]^{-1}\left[\sum_{i=1}^{N}\left(X-\hat{E}\left[X_{i} \mid I_{i}\right]\right)\left(T_{i}-\hat{E}\left[T_{i} \mid I_{i}\right]\right)\right]^{\prime} \\
\hat{g}\left(I_{i}\right)=\hat{E}\left[T_{i} / I_{i}\right]-E\left[X_{i} \mid I_{i}\right] \hat{\beta}
\end{gathered}
$$
}

When I instrument for income, the error term of the first stage regression is included in $X$ as well, see Yatchew (2003, p. 87). 
expect transfers, then they might adjust their labor and hence their income accordingly, in such a way that transfers determine income, leading to reverse causality ${ }^{19}$. Third, both the recipient and the donor incomes enter the transfer function, while in the dataset income is never observed for the two transfer partners. This results in an omitted variable bias, whose size and sign depend on the correlation between the recipient and the donor incomes.

To correct the first two sources of bias, I instrument for income following the approach used by Paxson (1992) to analyze household savings in Thailand. The approach consists of using longrun regional rainfall data and the household level information to identify the permanent and the transitory parts of income. Assuming that current rainfall deviation from its long-run mean is unpredictable, permanent household characteristics and annual decisions such as farm size and type of crops grown interacted with current deviations in rainfall provide a measure of the transitory income. This identification approach exploits the strong dependence of farm outcomes on rainfall (e.g. Alderman and Paxson, 1994; Fafchamps, Udry, and Czukas, 1998; Paxson, 1992). To the extent that production on different types of land responds differently to similar rainfall levels, and land allocation is made at the beginning of the season when rainfall level is unknown, land types and rainfall interactions could be used to derive unanticipated income shocks ${ }^{20}$. The approach has also the advantage of allowing a decomposition of income in permanent and transitory components 21 . Formally, denoting permanent by $P$ and transitory by $S$, the income equation is written as:

$$
I_{i r}=\beta_{t}+\beta_{0 r}+\beta_{1} X_{i r t}^{P}+\beta_{2} X_{i r t}^{S}+\beta_{3} Z_{i r t}+\varepsilon_{i r t}
$$

where $X^{P}$ represents characteristics that are permanent to the household, $X^{S}$ represents characteristics that determine transitory income, and $Z$ is a set of variables that influence both income and transfers. Variables in $Z$ are the household demographic, the head education, and his gender. As determinants of permanent income, I use livestock possessions (cattle, goats, and sheep), farm and other assets, and the type of crop grown as proxies for soil types. The transitory income determinants are rainfall deviations in the region and their interaction with $X^{P}$ and $Z$.

The main identification assumption is that the set of variables in $X^{P}$ and $X^{S}$ have no direct influence on transfers given or received, except through their effects on income. The estimated parameters are used to fit separately permanent and transitory incomes. The residual is the "unexplained" part of income (Paxson, 1992). Region fixed effects and rainfall variations are identified separately in regression 8 only when using the pooled sample (Paxson, 1992, p. 21). When the

\footnotetext{
${ }^{19}$ For instance, the household may purposely send some of its members in different locations to work and remit resources.

${ }^{20}$ Although information on illness incidence within the household could have been included, detailed information on illness spells was not available. Nevertheless, rainfall variability may capture the largest fraction of income risk in these areas.

${ }^{21}$ Rosenzweig and Wolpin (2000) address some of the limitations associated with using unanticipated rainfall variations to predict permanent and transitory income in areas where labor markets are nearly non-existent and family labor is important in farm income. I will return to these issues later when I discuss the empirical results.
} 
analysis is conducted for each year separately, it is assumed that rainfall deviations capture all regional fixed effects. For urban households, employment types, possession of durable goods (cars, motorbikes), and housing type are used to predict permanent income, and the residual is treated as transitory income. Therefore, the transitory income for urban households includes some elements of unexplained income. Estimation results for these first-stage regressions are shown in appendix B, in tables 15 and 16 for the rural and urban samples, respectively. It can be seen that in all regressions, the $F$ joint test on the significance of the instruments are significant at the 1 percent leve ${ }^{22}$. This suggests that the instruments used provide enough information to identify the income effects in the transfer function.

There is no information in the data sets which could be used to control effectively for the omitted variable bias. It is, however, to identify the sign of the bias and with reasonable assumption correlation between the recipient and the donor income, to determine the upper bound of bias. Consider the following linear specification of the transfer function.

$$
T_{i}=\alpha_{0}+\alpha_{1} I_{r i}+\alpha_{2} I_{d i}+\varepsilon_{i}
$$

If we abstract from the zero censoring and other specification issues, then OLS can be used to uncover consistent estimates from (9). When information for one party is missing, then instead of (9) one estimates the following:

$$
T_{i}=\alpha_{0}+\alpha_{1} I_{r i}+\mu_{i}
$$

where $\mu_{i}=\varepsilon_{i}+\alpha_{2} I_{d i}$

The estimates are consistent only if the omitted variable (the donor income) is not correlated with any covariate in equation (10). However, in general one might expect non-zero correlation between the donor and the recipient income, or between specific income components. In fact, it may be that these correlations motivate transfers in the first place. If we assume that only incomes are correlated, then the omitted variable bias can be expressed in standard form as:

$$
\hat{\alpha_{1}}=\alpha_{1}+\alpha_{2} \frac{\operatorname{cov}\left(I_{r}, I_{d}\right)}{\operatorname{var}\left(I_{r}\right)}
$$

In general, we expect $\alpha_{2}$ to be positive, thus implying that the sign of the bias is determined by the numerator in the last term at the right hand side of (11). Moreover, one can think of $\alpha_{2}=1$ as the limiting case, when the donor transfers all increment in his income to the recipient ${ }^{23}$. This implies that the upper limit of the bias is: $\frac{\operatorname{cov}\left(I_{r}, I_{d}\right)}{\operatorname{var}\left(I_{r}\right)}$.

From equation (11), it is apparent that instrumenting may not attenuate the omitted variable bias if the numerator (i.e. the covariance between the recipient and the donor income) is relatively

\footnotetext{
${ }^{22}$ Calculated F-statistics vary from 18.66 to 67.66 for the rural sample and from 12.01 to 42.00 for the urban sample

${ }^{23} \mathrm{Or} \partial T / \partial I_{r}=0$ in the relationship: $\partial T / \partial I_{d}-\partial T / \partial I_{r}=1$.
} 
large compared to the denominator (the variance of the recipient income) ${ }^{24}$. Cox and Rank (1992) and Cox and Jakubson (1995) compared estimates of (10) and (11) and concluded that the bias is positive and small. It appears that instrumenting attenuates the bias for transitory income but increases it for permanent income.

In discussing the omitted variable bias, I have assumed that the transfer function is actually linear and OLS would have delivered consistent estimates, in absence of omitted variables. However, the estimation strategies discussed previously do not rely extensively on OLS. Therefore, it is clear that the omitted variable bias given by equation (11) is not valid when one uses the limited dependent variable or the friction model.

I do not pursue an analytical derivation of the bias when the dependent variable is censored. Instead, I use Monte Carlo simulations to explore how sensitive the bias is under alternative estimation strategies: OLS applied to the net transfers, Tobit applied to one-side gross transfers, and Rosett Tobit applied to net transfers. The experiments assume that the data generation process follows an equation like (9) where $\alpha_{1}=-.3$ and $\alpha_{2}=.3$. The estimated version is equation (10), which corresponds to omitting the donor's income. The first set of experiments assumes zero covariance between donor and recipient income. The second set of experiments assumes that covariance is .25 between recipient and donor income. Estimations using OLS, Tobit, and Rosett Tobit are reported in table $\underline{6}$ for different sample sizes. Beneath the rows showing point estimates, are reported the standard errors and the absolute deviations from the true values.

- Insert table 6 about here.

The experiments suggest that OLS outperforms the other estimation methods if recipient and donor incomes are not correlated. However, when recipient and donor incomes are correlated, Rosett Tobit outperforms both OLS and the standard Tobit, both in terms of consistency and efficiency. Moreover, the relative performance of Rosett Tobit increases with the sample size. In light of these results, and given my sample size and the likelihood that income is correlated, I treat the Rosett Tobit results as my preferred estimates ${ }^{25}$.

A final concern with respect to identification is household size and composition. Although there are a number of reasons why it may not be desirable to treat the household composition as given, the concern is even more serious with respect to transfers. If observed household structure results from migration decisions and transfers received are correlated with the number of migrated members, then the coefficients of household composition are biased ${ }^{26}$. More specifically, if one

\footnotetext{
${ }^{24}$ In order to have an idea of the size of the bias, I use observed income, predicted permanent income, and predicted transitory income to approximate (11). The implied upper limit of the bias is .15 if one uses observed income. After instrumenting, the bias increases for permanent income (.17) and decreases for transitory income (.01)

${ }^{25}$ I do not present the Tobit estimates since the results are not significantly changed.

${ }^{26}$ For instance, it is a widespread practice for households to send members to the main city to look for off-farm jobs or to the neighboring Ivory Coast to work on the cash-crop plantations. In many instances, when migrants anticipate a short stay, for example, they may leave their wives behind and remit some money. This will lead to a positive correlation between household size and transfers received, and between female headship and transfers received.
} 
admits a positive relationship between transfers received and the number of household members who have migrated, then the direction of the bias depends on how observed household composition is related with the numbers of migrant members 27 . I do not attempt to control for the endogeneity of household structure with respect to transfers. Thus, the coefficients associated with these variables should be interpreted as correlations, at best providing only some suggestive evidence on the directions of the causal relationships.

\section{$5 \quad$ Results and discussions}

\section{$5.1 \quad$ Spline specifications}

Table 7 shows estimated transfer functions in rural areas. Estimation results for 1994 and 1998 are reported in the first four columns and in the middle four columns, respectively. Results for the pooled sample are shown in the last four columns. Transfer response to income is shown for the lowest to the highest income quartile, in rows one to four. For each set of results, the first pair of columns report OLS and IVE estimation results, ignoring the censored nature of the dependent variable. The second pair uses the Rosett Tobit in an attempt to control for the non-participation constraint. Looking across all regressions, it is apparent that ignoring the censoring understates the transfer response. Moreover, the friction coefficients are large and statistically significant. The results for urban households are presented in table 8 and in the same order as in table 7 . These two results put together suggest that the Rosett Tobit estimates are preferable, as indicated by the Monte carlo simulations discussed above.

- Insert tables 7 and 8 about here.

For the remaining of the results shown in these tables, I focus on the censoring-corrected estimates. For the 1994 rural sample, lowest income quartile group has the largest transfer response to income (-.27), when measured income is used in the estimations ${ }^{28}$. This relatively large effect drops to -.017 (column 4) when income is instruments for. And households in the second income quartile have the largest transfer response estimate, i.e. -.15 (column 4, row 3). Comparing the first four rows of columns seven and eight, it can be seen that estimated transfer response to income when one uses measured income are larger for relatively low-income households in contrast to the IVE

\footnotetext{
${ }^{27}$ Using the transfer function, the bias can be characterized as follows:
}

$$
E(T \mid x)=\beta_{1}+\beta_{2} x+\beta_{3} E(m \mid x)
$$

where $x$ is observed household members, and $m$ is the number of household members who have migrated, which was unobserved in the survey (hence unavailable to the researcher). Let us abstract from other explanatory variables and maintain that $\beta_{3}>0$. Then, OLS leads to an upward bias if $\frac{\partial m}{\partial x}>0$, to a downward bias if $\frac{\partial m}{\partial x}<0$, and to unbiased estimates if $\frac{\partial m}{\partial x}=0$. For instance, if I suppose that small households are small because of out-migration, then the estimates are upward biased. On the other hand, it may be that only at certain sizes do households let members migrate; in this case, there is an upward bias.

${ }^{28}$ Because the interest is on the response of transfer to income, conditional on transfer being made, the coefficients and not the marginal effects are used. 
estimates which predict a negligible income effect on transfer at low income level but a substantial effect for the middle income households. This pattern is supported by estimation results using the pooled sample (where the identification strategy is arguably more robust as earlier discussed). Transfer response to income in the lowest income quartile decreases from -.12 (and statistically significant at the five percent level) to -.02 (and not statistically significant) as one moves from column (11) to (12) along the first row. At the same time, the transfer derivative increases from -.13 to -.12 , and from -.03 to -.13 in the third and the fourth income quartiles, respectively. This pattern of results holds for the urban sample, shown in table 8. Restricting to the censoring-corrected estimates which I treat as my preferred ones, estimates using measured income clearly overstate the transfer response for the lowest income group. The transfer response to income decreases from -.34 to -.07 (not significant) in 1994, -..37 to -.17 in 1998 and from -.40 to -.14 for the pooled sample.

Abstracting from the relatively small size of the coefficients, these results have some implications on both the interpretation of transfer motives and policy decisions. It is apparent that estimates based on measured income are more consistent with altruistic transfers, which predict that transfer response to income is stronger the lower the recipient income (e.g. Cox, Hansen, and Jimenez, 2004). In terms of policy decisions, estimated transfer response using measured income implies that crowding effects may be larger for the lowest income groups, therefore the effect of public transfers to this group may be dampened by compensatory reduction in private transfers. These implications are rejected by the IVE estimations, which, however, depends on the validity of the identification strategy. More interestingly, the IVE estimates suggest that transfers do not react to income before one reaches the second income quartile, suggesting efficient public transfers (in terms of minimal crowding out effects) can be designed based on a set of observables which predict income.

In order to detect whether different income components have distinct effects on transfer, permanent and transitory income are entered separately in the regressions reported in tables 9 and 10 for rural and urban households, respectively. In each table, estimation results for 1994 and 1998 are presented in the first three and the following three columns, respectively. Estimation results using the pooled sample are shown in the last three columns. Conditional on transfer being made, one additional unit in recipient permanent income is met with a reduction of .14 and .12 unit of net transfers in 1994 and 1998, respectively, and .13 for the pooled sample. This suggests that average transfer response to permanent income is stable across years. In columns (3) and (6) for 1994 and 1998, respectively, and column (9) for the pooled sample, transfer response to permanent income varies by income quartile. There is some evidence that the permanent income does not matter for the lowest income group: the estimated coefficients are -.08, -.04, and -.05 in 1994, 1998, and for the pooled sample, respectively, and none is statistically significant. The absence of response in the lowest income group contrasts with the relatively large response in the second income quartile: -.25 in $1994,-.20$ in 1998 , and -.23 for the pooled sample. 
Results for urban households are presented in table 10. The transfer derivatives for the lowest income group are significant and larger than those for the lowest income group in the rural areas. For the 1994 sub-sample, the pattern is similar to that of rural households: transfer derivative for the lowest income group is smaller than that for the next two income groups. In 1998, transfer derivative for the lowest income group is larger than that of the second income quartile. Overall, these results suggest two caveats. First, the evidence suggests a stronger response of transfer to income in the middle income class, while transfer in the lowest income group is almost insensitive to income. This could be interpreted as a reflection of the observation made by Mahieu (2000), who reports that transfers in West Africa involve the upper class of the poor households and the lower class of the rich households. However, this is not consistent with the descriptive statistics (see tables 3 and 4) where transfer inflows to the lowest income quartile are the most important. A possible interpretation is that while transfer receipts are important for the lowest income group, transfer flows do not respond to income below a certain threshold leve ${ }^{29}$, implying that private transfers to these households are unlikely to be reduced in the event of public transfers. It is when households move into the next income class that substantial crowding-out effects are observed. Second, the response to permanent income remains relatively strong despite the presence of transitory income. This contradicts risk-sharing motivated transfers whereby all transfer activities are explained by transitory income shocks. Therefore it is likely that risk-sharing motives are not the only driving factor of observed transfers.

- Insert tables 9 and 10 about here.

The sixth row in each table contains transfer response to transitory income. The seventh and the eighth rows report transfer response to positive and negative transitory income, respectively 30. In rural areas, there is a sharp difference of transfer response to transitory income between the two years, -.05 in 1994 and -.17 in 1998, which contrasts with a rather stable response in urban areas (-.12 in 1994 and -.11 in 1998). In columns (2) and (3) for 1994 and (5) and (6) for 1998, positive

\footnotetext{
${ }^{29}$ Later partial linear estimation results provide more support for this interpretation.

${ }^{30}$ Rosenzweig and Wolpin (2000) discuss extensively the issues associated with using rainfall variations to identify permanent and transitory income components. In particular, they point out that if income is measured as farm gross output minus hired input costs, and family labor value is not accounted for, income variations due to rainfall may be overestimated. A simple characterization of the implied bias is as follows.

$$
\frac{d y}{d r}=\frac{\partial y}{\partial r}+\frac{\partial y}{\partial l} \frac{d l}{d r}
$$

where the unanticipated and exogenous response of income to rainfall is given by the first term of the RHS, which we assume is positive. The second term of the RHS is a product of labor marginal productivity $\left(\frac{\partial y}{\partial l}\right)$ and labor response to rainfall $\left(\frac{d l}{d r}\right)$. If this second term of the RHS is positive, my instruments over-state the changes in income entirely attributable to rainfall, that is, the role of transitory income will be overestimated.

For the specific context of Burkina, Udry (1996) using data from a sample of six villages find that marginal labor productivity is .31 for adult and .20 for child. Using the same data as in Udry (1996), Kazianga and Udry (2004) find a negative and insignificant labor response to rainfall variations: on average, annual total labor decreases by 16 hours for $100 \mathrm{~mm}$ deviation in rainfall. Together these results suggest that the transfer response to transitory income is upward biased (in absolute value), but the bias is not large enough to invalidate the conclusions that I draw.
} 
and negative shocks are permitted to have different effects. It can be seen that an increase of one unit in transitory income is met with reduction of 0.04 and .20 unit in net transfers in 1994 and in 1998, respectively, and .13 unit for the pooled sample, and the three coefficients are significant at the one percent level. A decrease of one unit in transitory income is met with an increase of .08 and .11 unit in net transfers in 1994 and 1998, respectively, and .11 unit for the pooled sample. The coefficients are significant for the 1998 sample and the pooled sample only. This suggests that only a small fraction of the transitory income may enter any risk-sharing pool, and in any case net transfers are far from completely compensating for changes in transitory income. This result may reflect the absence of efficient risk-sharing, a result which is supported by analysis from a smaller rural household sample from Burkina Faso (see Kazianga and Udry, 2004). Note, however, that while transfers given consecutive to positive shocks are entirely under the control of the respondent, transfers received in compensation of negative shocks are to a greater degree determined by the unobserved transfer partner. It is then likely that the omitted variable bias is larger for the latter estimate. Put together, the relatively weak transfer response to transitory income in 1994 and the relatively strong response in 1998 could indicate that transfers in compensation to income shocks do not take place immediately after harvest but later in the slack season, as observed by Ellsworth and Shapiro (1989) in a sample of villages in Burkina.

As noted before, the definition of transitory income for urban households includes elements of unexplained income components. However, as is apparent for rural households, the unexplained income component turns out to have a very small effect. It is apparent that on average, transfer response to permanent income is similar to that of rural households (about -.1 in 1994 and -.17 in 1998).

Turning to the friction coefficients, the negative ones can be interpreted as self-side giving costs while the positive ones could be interpreted as self-side receiving costs. The difference between the two coefficients (i.e. $\tau_{2}-\tau_{1}$ ) gives the size of transaction costs associated with transfers activities. In other words, individuals planning to make transfers less than the transaction costs refrain to do so. Using the estimates reported in table 9 and columns (3) and (6), these transactions costs are estimated at CFA 27494 in 1994 and at 30615 in 1998, for the rural sample. In urban areas, these transactions costs are evaluated at 81350 in 1994 and at 72004 in 1998 (see columns 3 and 6 , respectively) 31 . These estimates are, a priori, very large given the average observed transfer. There is however, a potential explanation to these large estimates. To the extent that current transfers carry future obligations, the transaction costs associated with transfers could be actually large, which justify the relatively large fraction of corner households 32 . That is in addition to the "actual" transaction costs individuals take into account all future discounted obligation costs associated with current transfer.

\footnotetext{
${ }^{31}$ Using estimation results in tables 7 and 8 give similar size of transactions costs

${ }^{32}$ ? and Fiske (1990) work in Burkina provides anecdotal account of the obligations associated with transfers. For an empirical analysis in different settings, see Foster and Rosenzweig (2001), for example
} 
For the remaining covariates, I focus on tables 9 and 10 for rural and urban households, respectively. The effect of the household head age provides additional support to the connection between transfer flows and the household life cycle. The head age and its squared term are jointly significant, and the signs imply a $U$ shaped transfer pattern, which is consistent with old-age support role of transfers. To the extent that household composition may be changing over the household life cycle, this suggests a possible connection between transfer flows and the household life cycle. As expected, there is positive correlation between transfers received and female headship (e.g. Cox and Jimenez, 1992). But as already discussed, the effects of household composition and head characteristics must be interpreted with caution.

The variable ruralresid captures out-migration to other rural regions, and is calculated as the number of individuals who have migrated from region $i$ to other rural areas divided by the number of households currently residing in province $i$. The variable cityresid measures out-migration to cities. In rural areas (ref. table 9 ), ruralresid is consistently positive and significant while cityresid is negative and only significant in 1994. The same pattern holds for urban households, although the the coefficients are not statistically significant. This is unexpected since a priori one may anticipate more transfer flows from cities to rural areas. However, it is possible that these variables are also conveying information related to regional economic opportunities. For example, economically more disadvantaged regions are more likely to supply migrants to other rural regions, and get in turn more remittances.

\subsection{Results from the A-I estimator}

Estimated transfer reactions based on the A-I estimator are presented in table 11 for rural households, and in table 5 for urban households. In each table, transfer reaction to permanent and to transitory income is shown in columns (1) to (3) and (4) to (6), respectively. Columns (1) and (2) present transfer response to recipient and donor permanent income, respectively. Column (3) reports the difference between columns (2) and (1), which is an estimate of the transfer response to a increase in one unit in the recipient income followed by a decrease of one unit in the donor income, conditional on transfers being received. Corresponding results are presented in columns (4)-(6) for transitory income, conditional on transfers being given out. Results for 1994 and 1998 are shown in the top and the middle panels, respectively. Estimation results for the pooled sample are presented in the bottom panel. The derivatives are evaluated at the sample mean and for each income quartile. The standard errors (reported in brackets for the sample average estimates) indicate that the coefficients are precisely estimated for the overall sample. They are less precise, however when one considers income quartiles.

- Insert table 11 about here.

-Insert table 12 about here.

It is apparent from columns (1) and (2) that transfers are less responsive to changes in recipient 
permanent income than to changes in the donor permanent income, a result which is stable for the two years and for the pooled sample. This is expected since the donor is likely to have more control over transfers given than the recipient is over transfers received, and information was available for only one transfer partner. Looking at column (2), transfer response to permanent income decreases with income level in 1994 (i.e. immediately after harvest) but increases with income in 1998, i.e. during the leaning season. While transfer pattern in 1994 is more consistent with altruistic behavior whereby there is a larger transfer derivative for low income households, transfer derivatives in 1998 are more consistent with exchange behavior, i.e. increasing with income level. This puzzling pattern could result from if poor households transfer to rich households immediately after harvest in order to induce reciprocal gifts during the leaning season. It could also be the other way around: poor households are paying back implicit loans contracted from rich households during the leaning season. However, in absence of detailed information on the transfer partners and the timing of the transfers these results must be interpreted with caution.

Columns (4)-(6) show the transfer reaction to transitory income. It can be seen that transitory income loss is met with little transfer, on average a decrease of CFA in transitory income is met with CFA .03 in 1994 and CFA 0.08 in 1998. In contrast, on average CFA .23 and CFA .09 is given out of each additional CFA of transitory income. For the two years, the fraction of additional transitory income which is transferred out increases with income level, households in the highest income group transfer out relatively more transitory income than households in the lowest. There are noticeable changes between 1994 and 1998 for only the first and fourth income quartiles.

Estimated transfer derivatives are reported in columns (3) and (6) for permanent and transitory income, respectively. Suppose that transfers flow from the fourth to the first income quartile. The results imply that if transitory income drops one unit in the fourth quartile and increases one unit in the first, then there is a reduction of .48 unit in transfer flows. Similar changes in permanent income imply that transfers are reduced by .15 unit, a figure which is close to that reported by Altonji, Hayashi, and Kotlikoff (1997) for the United States.

Results for urban households are presented in table 12, The first caveat is that transfer derivatives are much larger than those of rural areas, a result which is consistent with the estimates presented so far. For the highest income quartile, the hypothesis that public transfers are neutralized by compensatory effects of private transfers could not be ruled out. The main fact is that wealthier households donate more from additional income, suggesting that changes in donor behavior drives the crowding-out pattern. Note that the crowding effect will still hold even if one assumes that transfers flow from the highest to the lowest income quartile.

In fact, in 1998 transfer is almost insensitive to permanent income for households in the lowest quartile. Yet, considering the two years together and keeping in mind the timing of the survey may suggest another interpretation. It is conceivable that poor households transfer out immediately after harvest in anticipation of reciprocal gifts from the wealthier later in the slacking season. 
This interpretation is consistent with the idea of induced altruism formalized by Stark and Falk (2000) and both anthropological (Hammond, 1966) and quantitative (Ellsworth and Shapiro, 1989) description of transfer patterns in Burkina Faso.

\subsection{Partial linear estimations}

Estimated transfer responses to income using the partial linear approach are reported in figures 1 to 4, for permanent and transitory income and in rural and urban areas. In each set of figures, the top panel shows estimates of 1994 and 1998, respectively, and the bottom panel shows estimates using the pooled sample. In each panel the distribution of the relevant income measure is plotted against the right-hand side $y$ axis.

- Insert figures 1 and 2 about here

In figure 1, the pattern shows a weak response of transfer to income at low income levels, followed by a sharp negative response and then a pattern which is close to an inverted $U$. This last segment covers, however, a small fraction of the income distribution. In essence, the pattern suggests that the strongest response of transfers to permanent income occurs only for the middle income group, a finding which was already suggestive in the parametric estimations. Figure 2 depicts transfer response to permanent income in urban areas. In contrast to rural areas, the transfer response monotonically decreases until one reaches high income level (above CFA 232,000 in 1994 and CFA 220,000 in 1998). Thus, for the largest fraction of urban residents, there is strong negative transfer response to income.

Transfer response to transitory income in rural areas is reported in figure 3. In each year, for transitory income loss above CF 40,000 there is a sharp negative response of transfer. Above this threshold, the transfer reaction is rather weak, and becomes substantial when transitory income gains reach around CFA 55,000. A possible explanation of this pattern is that transfers compensate transitory income variations only when the loss or the gain reaches a certain threshold; in other words, there is a range of income shocks within which one may not observe risk-sharing. This will be the case if only large losses or gains are observed or if households are able to auto-insure against relatively small shocks. The pattern uncovered for urban households (see 4) is similar to that of rural households. In each case, however, only a small fraction of the households are subject to such large shocks. This might explain the weak response of transfers to income uncovered by the parametric approach.

- Insert $\underline{3}$ and $\underline{4}$ about here

\section{Conclusion}

This paper sought to describe the extent and pattern of private transfers in Burkina Faso, a low-income country with virtually no formal public transfer system but with a long tradition of 
gift giving. The data used for the empirical work were from existing household survey datasets collected in 1994 and 1998. The analysis was concerned with the motives for private transfers and, in particular, to what extent they would be "crowded out" by public transfers and other government programs. The paper aimed also to contribute to the econometric analysis of transfer behavior by using a multifaceted estimation approach.

The empirical work used two national surveys conducted in 1994 and 1998. The estimation focused on the response of net transfers (measured as transfers received minus transfers given) to recipient permanent and transitory income. The findings suggested that transfers flow primarily from more affluent to less affluent households, implying that private transfers might have some income equalizing effects. There is a significant and negative relationship between net transfers and recipient permanent income. The magnitude of the response, however, varies greatly by income level. It is, in particular insignificant at the lowest income and the most important at the middle income level. Transfer response to transitory income varies between the two years, although there is a common pattern which indicates that transfers react only to large income shocks, either positive or negative, which in each year concern a small fraction of the households.

These findings have implications on both our understanding of transfer behavior and policies which seek to influence the income distribution, although they must interpreted with caution since they hinge on the validity of my identification strategy. The evidence suggests that altruistic transfers, whereby transfers are reduced if the recipient income increases, are not observed below a certain income threshold. In other words, for the poorest households, a marginal increase in income does not influence the amount of transfers received. Such transfer pattern suggests that effective public transfers targeting the poorest households are feasible. Transfer response to transitory income becomes important only if shocks are relatively large. In the wake of the renewed interest in risk management in Africa (already mentioned), this suggests that crowding out of informal insurance mechanisms are more likely if outside interventions target large shocks but could be minimized by targeting moderate shocks which are more common and are less insured through private transfers. 


\section{References}

Alderman, H., and C. H. Paxson (1994): "Do the Poor Insure? A Synthesis of the Literature on Risk and Consumption in Developing Countries," in Economic in a Changing World, ed. by E. L. Bacha, vol. Development, Trade and the Environment, chap. 3, pp. 48-78. Macillan, London.

Altonji, J., F. Hayashi, and F. Kotlikoff (1997): "Parental Altruism and Inter Vivos Transfers: Theory and Evidence," Journal of Political Economy, 105(6), 1121-1166.

Altonji, J. G., and H. Ichimura (2000): "Estimating Derivatives in Nonseparable Models with Limited Dependent Variables," Mimeo.

Ancey, G. (1983): Monnaie et Structure d'Exploitation en Pays Mossi: Haute Volta. Editions de l'Office de la Recherche Scientifique et Thechnique Outre-Mer.

Badini, K. F. (2004): "Contrat entre les Generations et Securite Sociale Locale des Personnes agees en Milieu Rural Burkinabe," Papier Presente a la Conference "Debats Nord-Sud: Relations de Securite Sociale et Genre", Ouagadougou, Burkina Faso,15-16 Decembre 2003.

Barro, R. J. (1974): “Are Government Bonds Net Wealth?," Journal of Political Economy, 82(4), $1095-1117$.

Becker, G. S. (1974): "A Theory of Social Interactions," Journal of Political Economy, 82(4), 1063-1094.

Cochrane, J. H. (1991): "A Simple Test of Consumption Insurance," Journal of Political Economy, 99(5), 957-76.

Cox, D. (1987): "Motives for Private Income Transfers," Journal of Political Economy, 95(3), $508-46$.

Cox, D., B. E. Hansen, and E. Jimenez (2004): "How Responsive are Private Transfers to Income: Evidence from a Laissez-Faire Economy," Journal of Pulic Economics, 88(9-10), 21932219 .

Cox, D., And G. Jakubson (1995): "The Connection between Public Transfers and Private Interfamily Transfers," Journal of Public Economics, 57(1), 129-67.

Cox, D., And E. Jimenez (1992): "Social Security and Private Transfers in Developing Countries: The Case of Peru," World Bank Economic Review, 6(1), 155-69. 
(1995): "Private Transfers and the Effectiveness of Public Income Redistribution in the Philippines," in Public spending and the poor: Theory and evidence, ed. by D. van de Walle, and K. Nead, pp. 321-46. Johns Hopkins University Press for the World Bank, Baltimore and London.

Cox, D., And M. R. RANK (1992): "Inter-vivos Transfers and Intergenerational Exchange," Review of Economics and Statistics, 74(2), 305-14.

Ellsworth, L., And K. Shapiro (1989): "Seasonality in Burkina Faso Grain Marketing: Farmer Strategies and Government Policies," in Seasonal Variability in Third Wordl Agriculture, ed. by D. E. Sahn. Jonh Hopkins University Press, Baltimore.

Fafchamps, M., C. Udry, and K. Czukas (1998): "Drought and Saving in West Africa: Are Livestock a Buffer Stock?," Journal of Development Economics, 55(2), 273-305.

FAn, J. (1992): "Design-Adaptative Nonparametric Regression," Journal of the American Statistical Association, 97, 998-1004.

Fiske, A. P. (1990): "Relativity within the Moose ("Mossi") Culture: Four Incomensurable Modelss for Social Relationships," Ethos, 18(2), 180-204.

Foster, A. D., And M. R. Rosenzweig (2001): "Imperfect Commitment, Altruism, and the Family: Evidence from Transfer Behavior in Low-Income Rural Areas," Review of Economics and Statistics, 83(3), 389-407.

Greene, W. (1997): Econometric Analysis. Prentice Hall, New Jersey, USA, 3 edn.

Hammond, P. (1966): Yatenga: Thechnology in the Culture of a West African Kingdom. The Free Press, New York.

Harragin, S. (2004): "Relief and Understanding of Local Knowledge: The Case of Southern Sudan," in Culture and Public Action, ed. by V. Rao, and M. Walton, chap. 14, pp. 307-327. Stanford University Press.

Honore, B. E., E. Kyriazidou, and C. Udry (1997): "Estimation of Type 3 Tobit Models using Symmetric and Pairwise Comparisons," Journal of Econometrics, 75, 107-128.

Kazianga, H., And C. Udry (2004): "Consumption Smoothing and Livestock in Rural Burkina Faso," Paper Presented at Center for the Study of African Economies Annual Meeting, March 21-22, University of Oxford, UK.

Lucas, R. E. B., And O. Stark (1985): "Motivations to Remit: Evidence from Bostwana," Journal of Political Economy, 93(5), 901-918. 
MACE (1991): "Full Insurance in the Presence of Aggregate Uncertainty," Journal of Political Economy, 99(5), 928-956.

Maddala, G. S. (1983): Limited-Dependant and Qualitative Variables in Econometrics. Cambridge University Press, New York, 1 edn.

Mahieu, F. R. (2000): "Altruism and Poverty in an African Context," in The Economics of Reciprocity, Giving and Altruism, ed. by L. A. Gerard-Varet, S. C. Kolm, and J. M. Ythier, chap. 10, pp. 196-203. MacMillan Press.

Nicholson, S. E., And I. M. Paolo (1993): "A Re-Evaluation of Rainfall Variability in the Sahel. Part I. Characteristics of Rainfall Fluctuations," International Journal of Climatology, 13(4), 371-389.

Paxson, C. H. (1992): "Using Weather Variability to Estimate the Response of Saving to Transitory Income in Thailand," American Economic Review, 82(1), 15-33.

Ravallion, M. (2003): "Targeted Transfers in Poor Countries: Revisiting the Trade-Offs and Policy Options," Social Protection Discussion Paper Series 314, Social Protection Unit, Human Development Network, The World Bank, Washington, DC. USA.

Riesman, P. (1974): Societe et Liberte chez les Peul Djelgobe de Haute Volta: Essai d'Anthropologie Introspective. Mouton and Co. et Ecole Pratique des Hautes Etudes, Paris, France.

Robinson, P. M. (1988): "Root-N-Consistent Semiparametric Regression," Econometrica, 56(4), 931-954.

Rosenzweig, M. R., And K. I. Wolpin (2000): "Natural Natural Experiments in Economics," Journal of Economics Litterature, 38(4), 827-874.

Rosett, R. (1959): "A Statistical Model of Friction in Economics," Econometrica, 27(1), 263-267.

SAul, M. (1981): "Beer, Sorghum and Women: Production for the Market in Rural Upper Volta," Africa, 6(3), 746-764.

(1983): "Work Parties, Wages, and Accumulation in a Voltaic Village," American Ethnologist, 10(1), 77-96.

Shipton, P. (1990): "African Famines and Food Security: Anthropological Perspectives," Annual Review of Anthropology, 19, 353-394. 
Stark, O., and I. Falk (2000): "Transfers, Empathy Formation, and Reverse Transfers," in The Economics of Reciprocity, Giving and Altruism, ed. by L. A. Gerard-Varet, S. C. Kolm, and J. M. Ythier, chap. 8, pp. 174-181. MacMillan Press.

Townsend, R. M. (1994): "Risk and Insurance in Village India," Econometrica, 62(3), 539-91.

UDRY, C. (1994): "Risk and Insurance in a Rural Credit Market: An Empirical Investigation in Northern Nigeria," Review of Economic Studies, 61, 495-526.

(1996): "Gender, Agricultural Production and the Theory of the Household," Journal of Political Economy, 104(5), 1010-1046.

Varet-Gerard, L. A., S. C. Kolm, and J. M. Ythier (eds.) (2000): The Economics of Reciprocity, Giving and Altruism, no. 130 in International Economic Association Conference. MacMillan Press.

World Bank (2001): "Dynamic Risk Management and the Poor: Developing a Social Protection Strategy for Africa," Report 28144-BUR, Africa Region Human Development Department, The World Bank, Washington, D. C., USA. (2004): "Burkina Faso Risk and Vulnerability Assessment," Report, Africa Region Human Development Department, The World Bank, Washington, D. C., USA.

Yatchew, A. (2003): Semiparametric Regression for the Applied Econometrician. Cambridge University Press, New York. 
Table 1: Household participation in transfers, 1994 and 1998

\begin{tabular}{lrrrr} 
& $(1)$ & 2 & \multicolumn{3}{c}{3} & 4 \\
\hline \hline & \multicolumn{2}{c}{ Rural } & \multicolumn{2}{c}{ Urban } \\
& 1994 & 1998 & 1994 & 1998 \\
Non participants & 61.72 & 57.4 & 59.6 & 56.47 \\
As recipients only & 23.01 & 27.59 & 12.54 & 17.01 \\
As donors only & 8.35 & 9.02 & 21.85 & 20.86 \\
As both & 6.92 & 5.99 & 6.01 & 5.67 \\
Number households & 4956 & 5465 & 2193 & 2267 \\
\hline \hline
\end{tabular}


Table 2: Monthly distribution of transfer given

\begin{tabular}{lrrrr} 
& $(1)$ & $(2)$ & $(3)$ & $(4)$ \\
\hline \hline Rural & Frequency & Transfer size & t-test & $\mathrm{N}$ \\
1994 & 15.27 & 2922.28 & & 5003 \\
October & 11.11 & 2191.49 & 0.68 & 207 \\
November & 16.12 & 3759.10 & 1.70 & 1526 \\
December & 14.86 & 2178.10 & 2.32 & 1686 \\
January & 15.43 & 3005.26 & 0.19 & 1581 \\
& & & & \\
1998 & 15.01 & 3047.60 & & 5523 \\
May & 11.61 & 2658.28 & 0.80 & 1266 \\
June & 17.09 & 3111.39 & 0.20 & 2130 \\
July & 14.95 & 3215.43 & 0.50 & 2127 \\
Urban & & & & \\
1994 & 27.86 & 7976.89 & & 2144 \\
October & 30.53 & 6734.12 & 1.02 & 237 \\
November & 34.76 & 9818.82 & 2.49 & 708 \\
December & 22.97 & 6434.51 & 2.55 & 838 \\
January & 24.02 & 8782.80 & 0.63 & 361 \\
& & & & \\
1998 & 26.53 & 8119.76 & & 2278 \\
May & 26.03 & 7909.75 & 0.29 & 646 \\
June & 26.22 & 8168.47 & 0.07 & 677 \\
July & 28.04 & 8145.02 & 0.04 & 818 \\
August & 21.32 & 8718.48 & 0.29 & 137 \\
\hline \hline
\end{tabular}


Table 3: Transfer impact on household income, rural areas

\begin{tabular}{lrrrr}
\hline \hline & \multicolumn{2}{c}{ Income } & Net Transfer & Perc. income \\
1994 & & & \\
Non Participants & 36034 & 36034 & 0 & 0.00 \\
Recipients & 31601 & 39915 & 8314 & 26.31 \\
Donors & 70066 & 56482 & -13585 & -19.39 \\
Both recipients and donors & 68105 & 67405 & -699 & -1.03 \\
& & & & \\
1st quartile & 26761 & 28168 & 1407 & 5.26 \\
2nd quartile & 29104 & 30734 & 1630 & 5.60 \\
3rd quartile & 36982 & 38244 & 1262 & 3.41 \\
4th quartile & 67704 & 66193 & -1511 & -2.23 \\
& & & & \\
1998 & & & & \\
Non Participants & 58509 & 58509 & 0.0 & 0.00 \\
Recipients & 42874 & 51190 & 8316.4 & 19.40 \\
Donors & 100428 & 84513 & -15915.2 & -15.85 \\
Both recipients and donors & 75190 & 74144 & -1045.4 & -1.39 \\
& & & & \\
1st quartile & 36162 & 38801 & 2639 & 7.30 \\
2nd quartile & 47855 & 49969 & 2114 & 4.42 \\
3rd quartile & 59768 & 61694 & 1926 & 3.22 \\
4th quartile & 92159 & 88654 & -3505 & -3.80 \\
\hline \hline
\end{tabular}


Table 4: Transfer impact on household income, urban areas

\begin{tabular}{|c|c|c|c|c|}
\hline & \multicolumn{2}{|c|}{ Income } & \multirow[t]{2}{*}{ Net Transfer } & \multirow[t]{2}{*}{ Perc. income } \\
\hline & Pre-transfer & Post-transfer & & \\
\hline \multicolumn{5}{|l|}{1994} \\
\hline Non Participants & 136395 & 136395 & 0 & 0.00 \\
\hline Recipients & 92250 & 106190 & 13940 & 15.11 \\
\hline Donors & 190203 & 178470 & -11734 & -6.17 \\
\hline Both recipients and donors & 158408 & 164208 & 5801 & 3.66 \\
\hline 1st quartile & 51001 & 53210 & 2209 & 4.33 \\
\hline 2nd quartile & 95363 & 96538 & 1175 & 1.23 \\
\hline 3rd quartile & 148191 & 148734 & 543 & 0.37 \\
\hline 4th quartile & 262038 & 260111 & -1927 & -0.74 \\
\hline \multicolumn{5}{|l|}{1998} \\
\hline Non Participants & 148859 & 148859 & 0.0 & 0.00 \\
\hline Recipients & 94879 & 110161 & 15281.7 & 16.11 \\
\hline Donors & 172355 & 158944 & -13411.0 & -7.78 \\
\hline Both recipients and donors & 221612 & 223578 & 1966.2 & 0.89 \\
\hline 1st quartile & 54651 & 57986 & 3335 & 6.10 \\
\hline 2nd quartile & 95623 & 98213 & 2590 & 2.71 \\
\hline 3rd quartile & 140363 & 142196 & -5471 & -3.90 \\
\hline 4th quartile & 287290 & 284759 & -2532 & -0.88 \\
\hline
\end{tabular}


Table 5: Transfers effects on income distribution

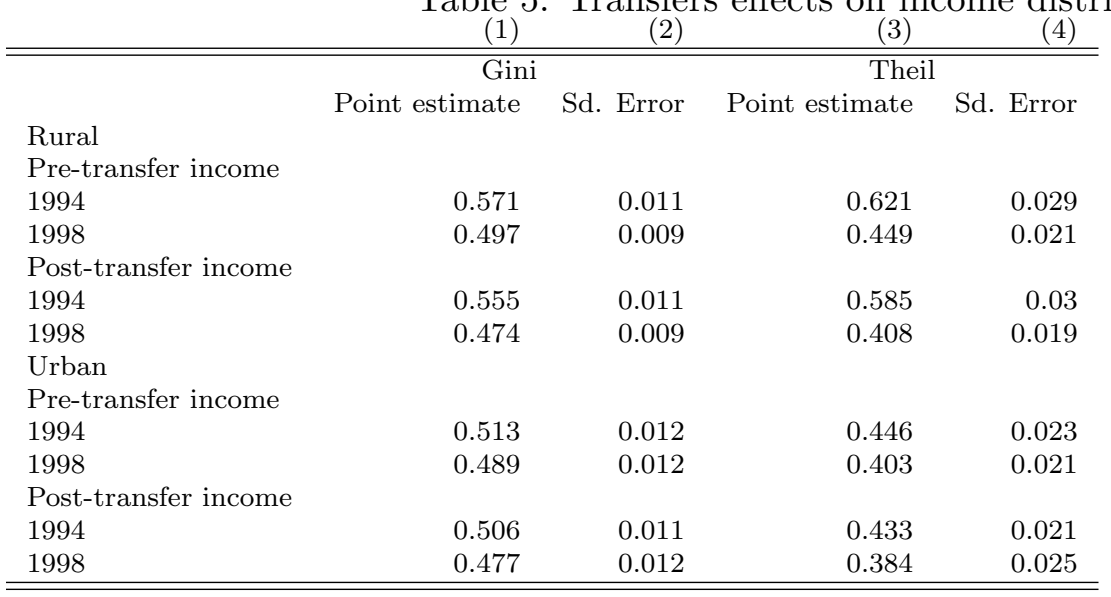


Table 6: Monte Carlo evaluation of omitted variable bias

\begin{tabular}{lrrrrrr}
\hline \multirow{3}{*}{ Sample size } & \multicolumn{3}{c}{$\operatorname{Cov}\left(I_{d}, I_{r}\right)=0$} & \multicolumn{3}{c}{$\operatorname{Cov}\left(I_{d}, I_{r}\right)=.25$} \\
100 & OLS & Tobit & Rosett & OLS & Tobit & Rosett \\
& -0.302 & -0.333 & -0.379 & -0.226 & -0.250 & -0.286 \\
& {$[.107]$} & {$[.124]$} & {$[.141]$} & {$[.107]$} & {$[.122]$} & {$[.141]$} \\
\multirow{3}{*}{1000} & {$[.085]$} & {$[.101]$} & {$[.129]$} & {$[.104]$} & {$[.105]$} & {$[.112]$} \\
& -0.302 & -0.333 & -0.378 & -0.227 & -0.251 & -0.286 \\
& {$[.033]$} & {$[.038]$} & {$[.043]$} & {$[.033]$} & {$[.038]$} & {$[.043]$} \\
10000 & {$[.026]$} & {$[.042]$} & {$[.0795]$} & {$[.073]$} & {$[.052]$} & {$[.036]$} \\
& -0.299 & -0.330 & -0.374 & -0.224 & -0.248 & -0.281 \\
& {$[.010]$} & {$[.012]$} & {$[.013]$} & {$[.011]$} & {$[.012]$} & {$[.014]$} \\
& {$[.008]$} & {$[.030]$} & {$[.074]$} & {$[.076]$} & {$[.052]$} & {$[.019]$} \\
\hline
\end{tabular}




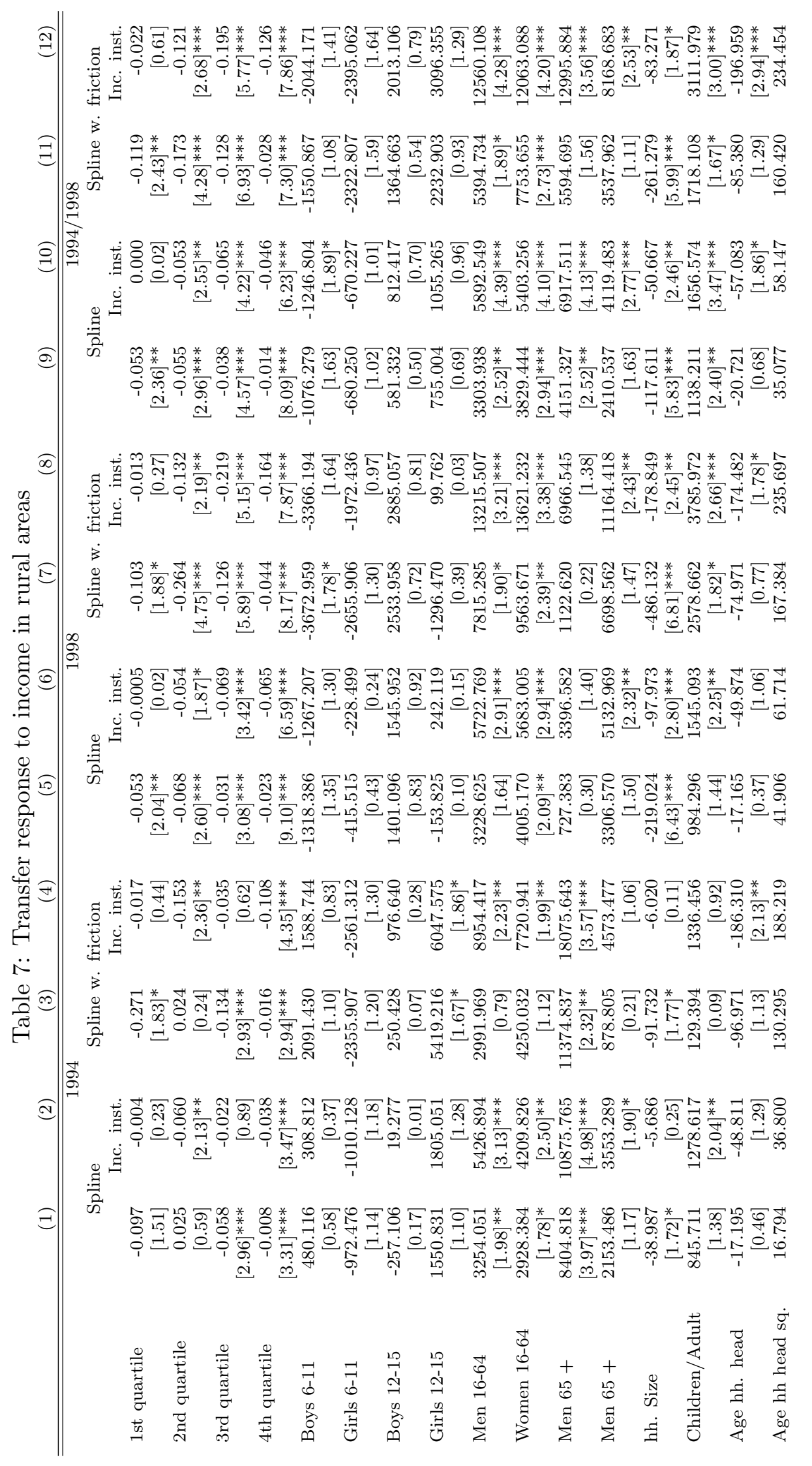




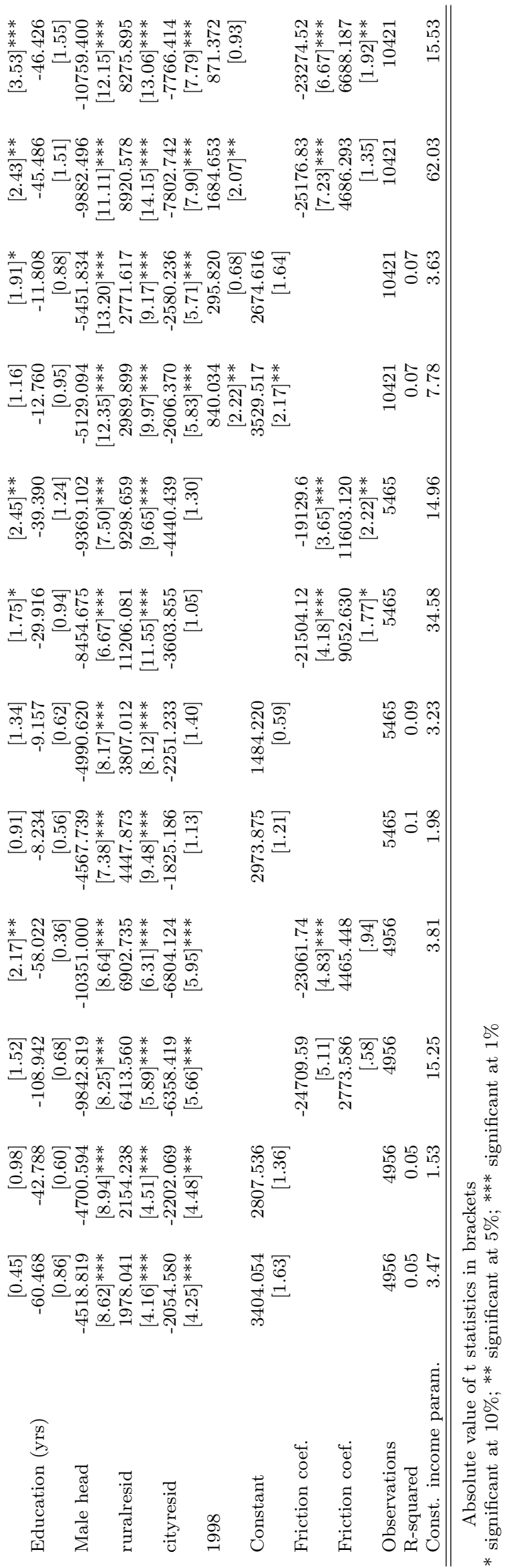




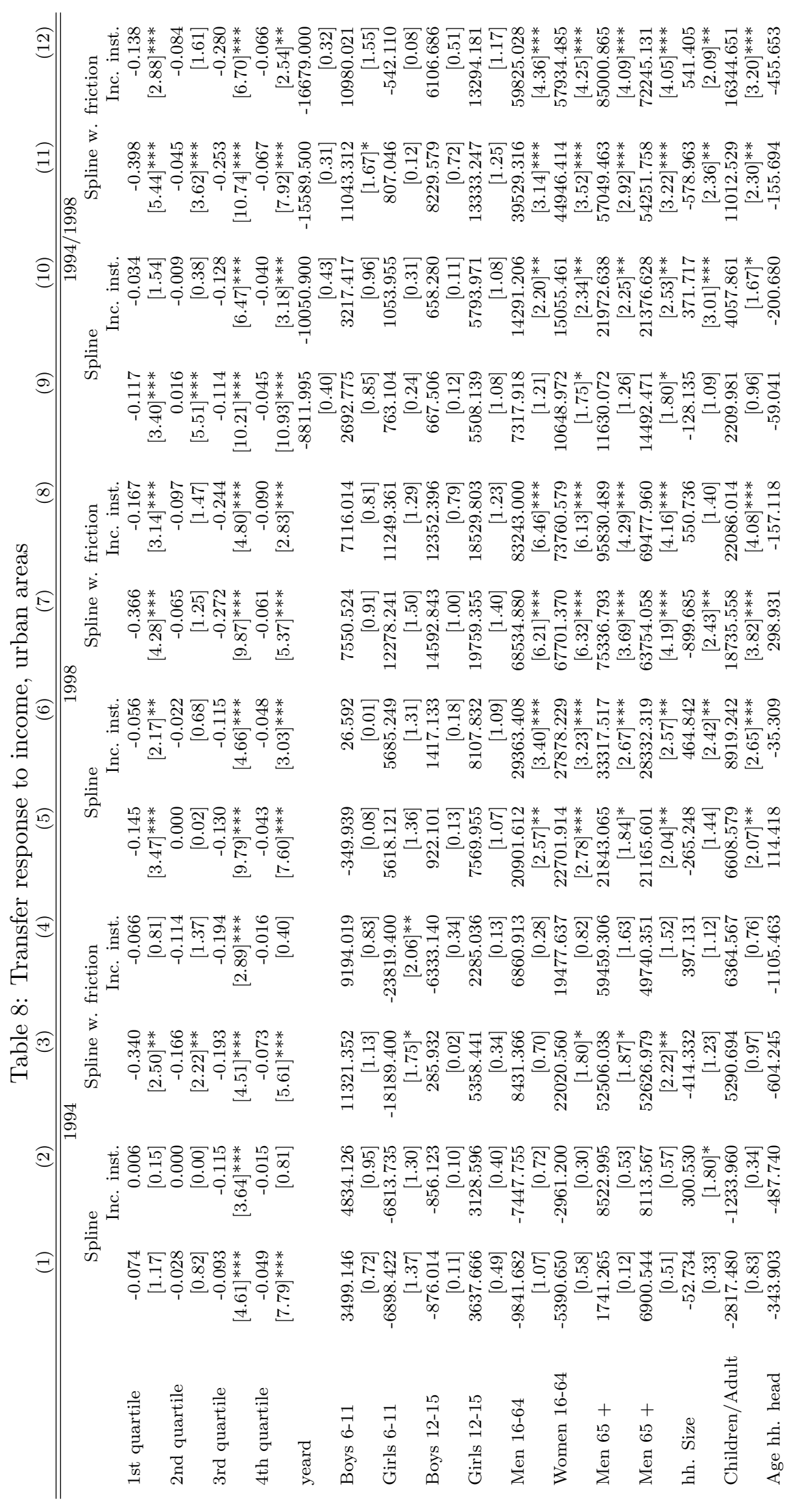




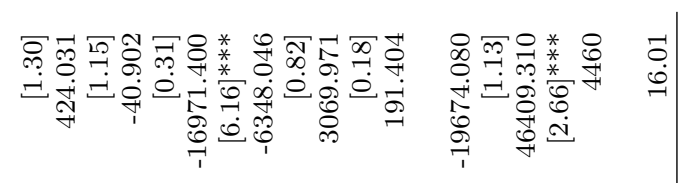

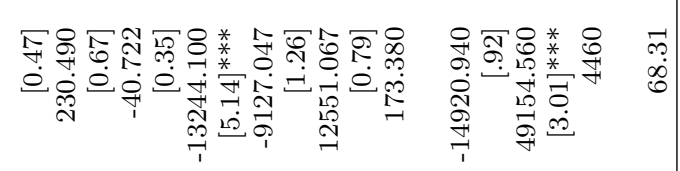

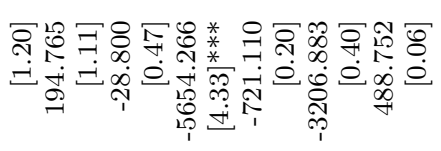

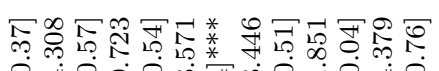

๑

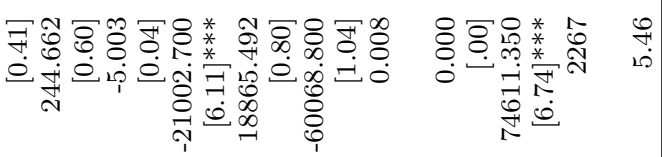

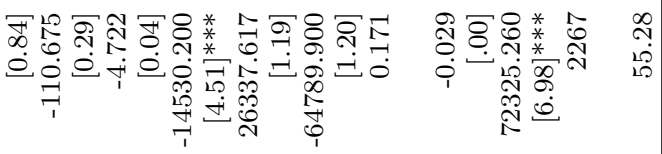

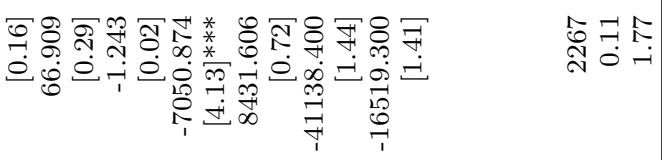

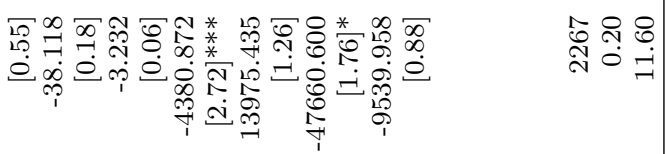

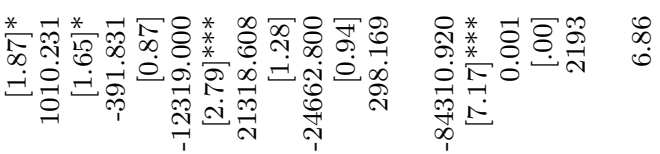

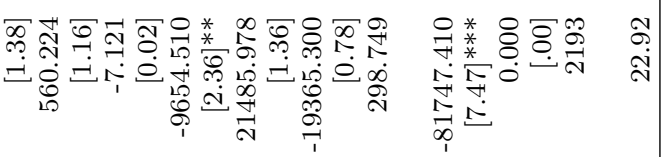

*

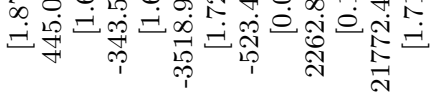

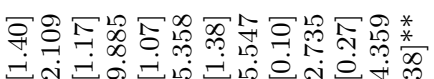

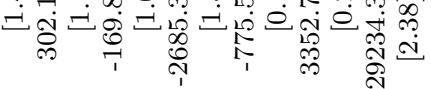

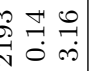

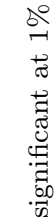

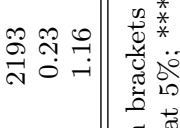

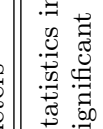

$\underset{*}{*}$

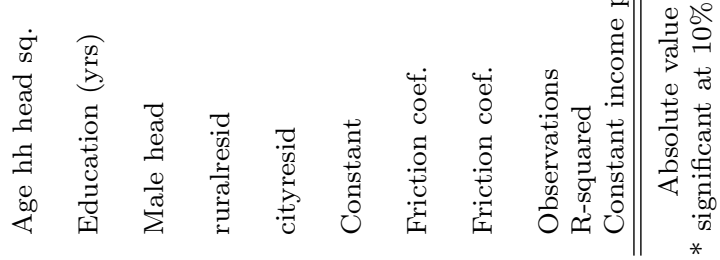




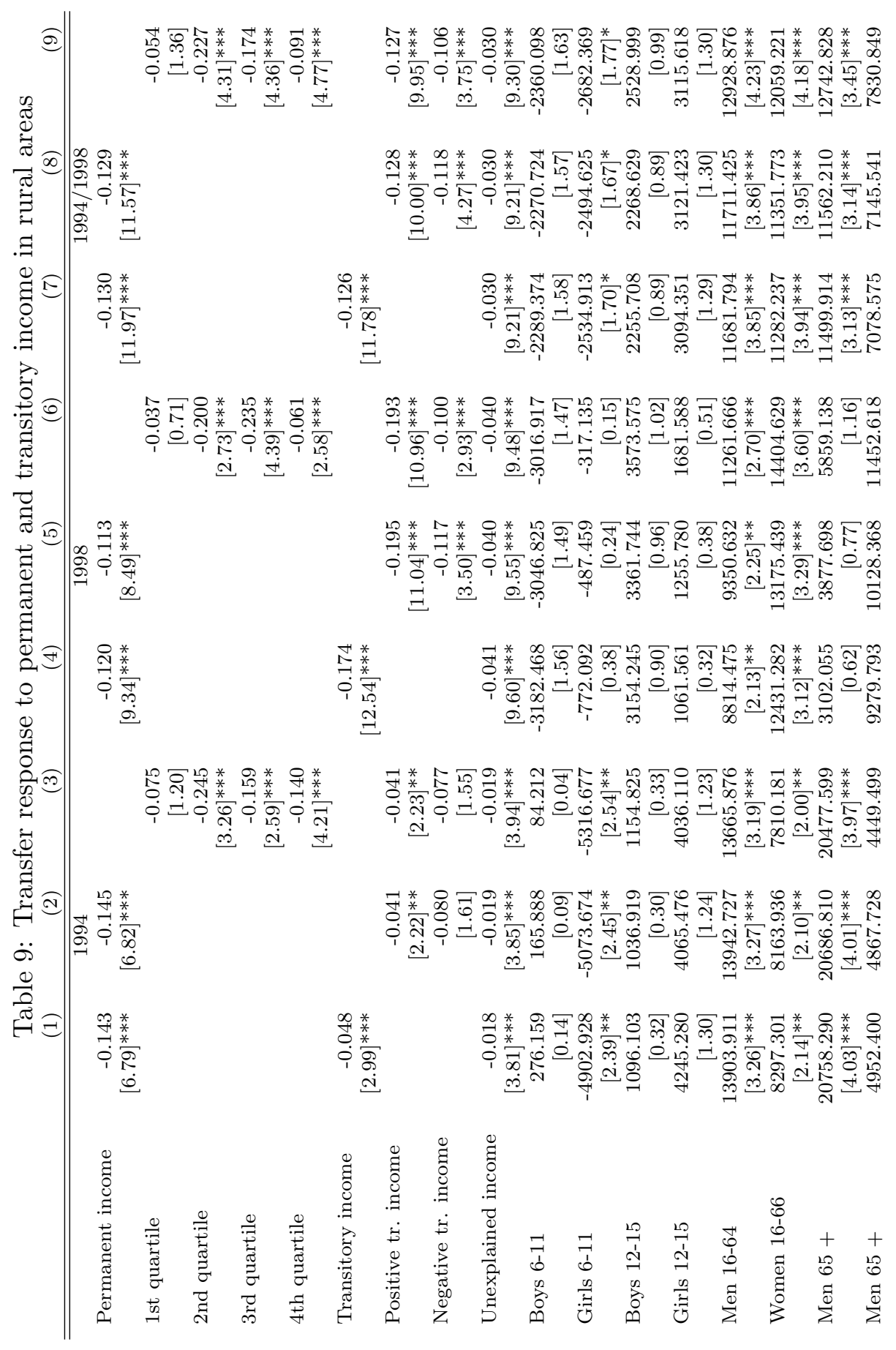




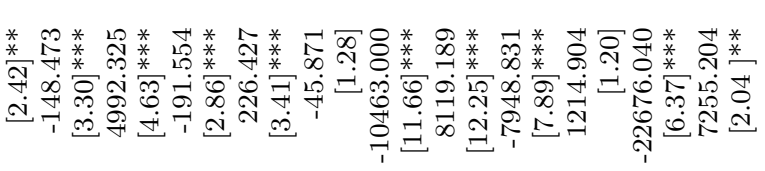

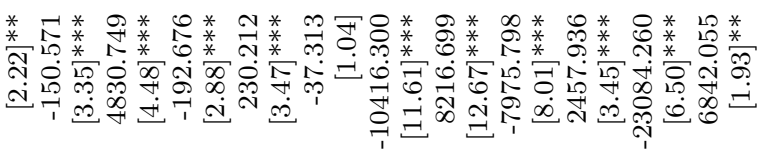

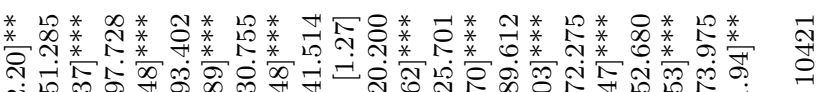

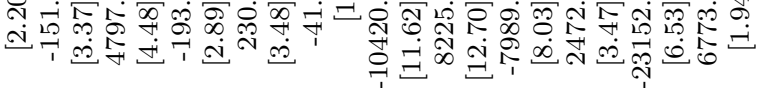

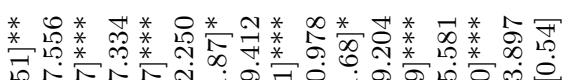

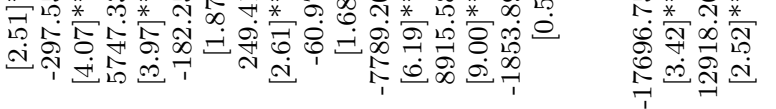

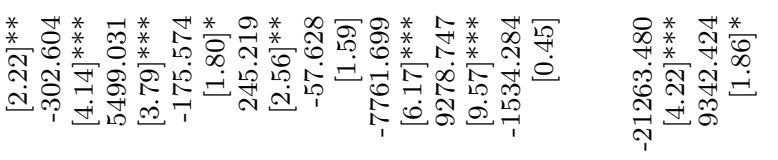
공

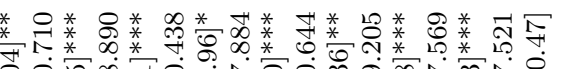

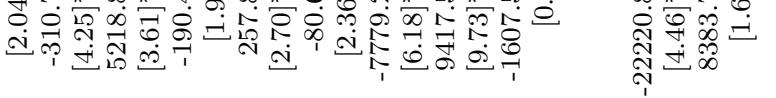

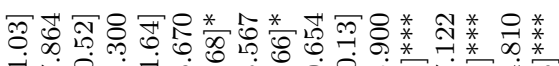

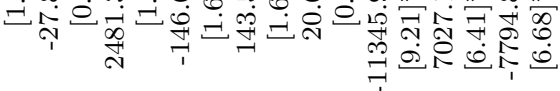

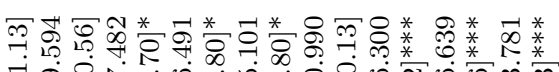

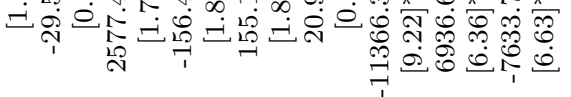

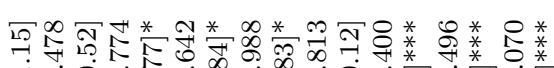

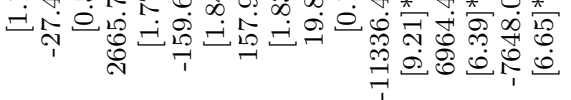

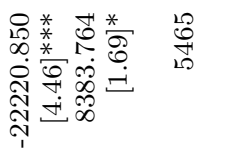

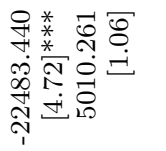

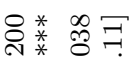
융영 สู่ 密 


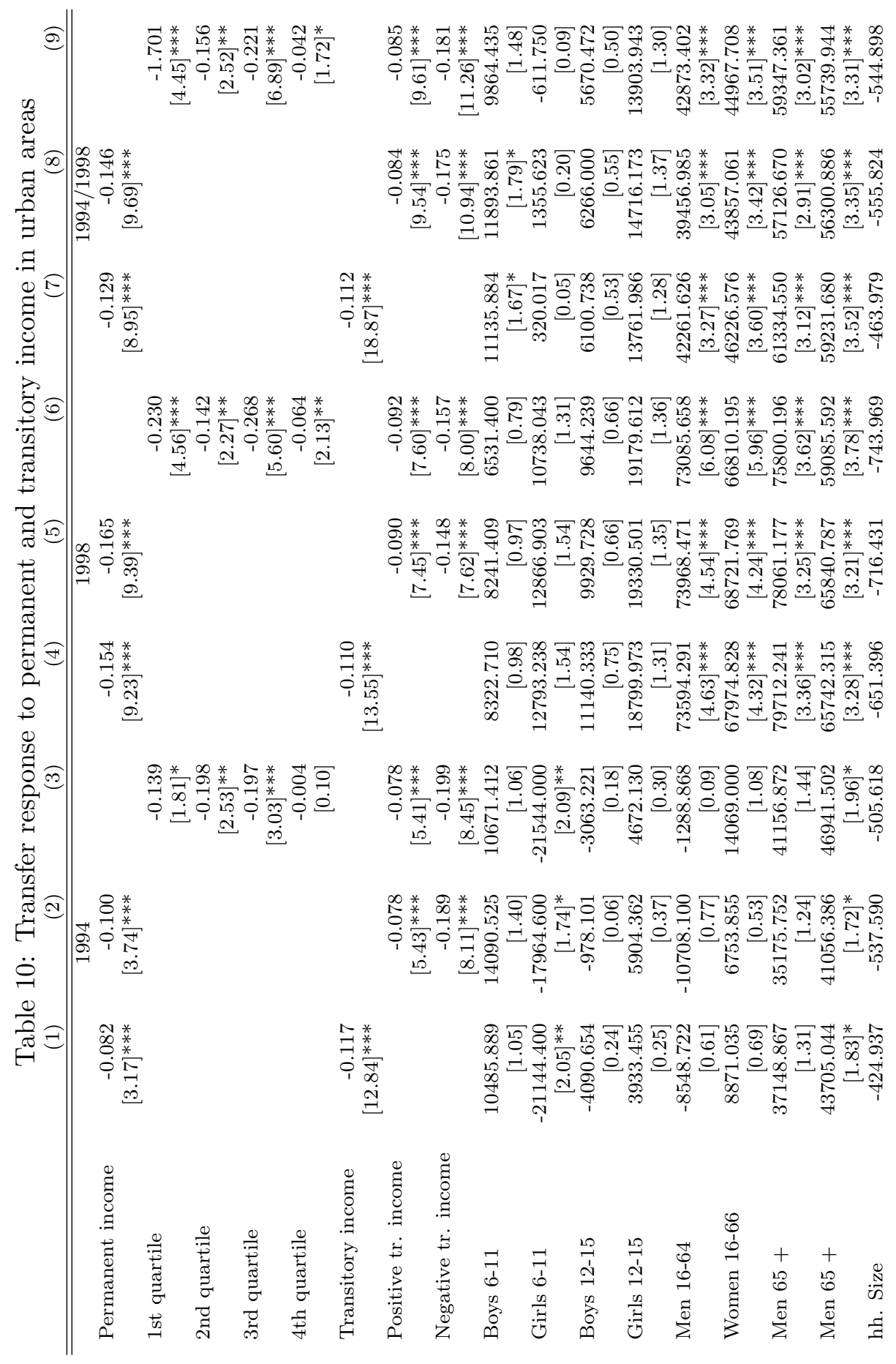




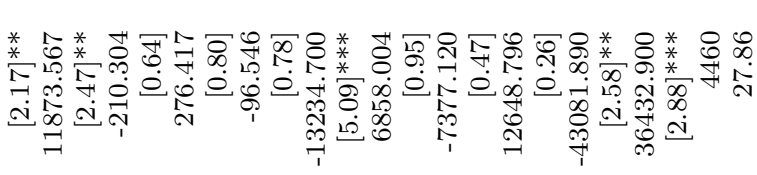

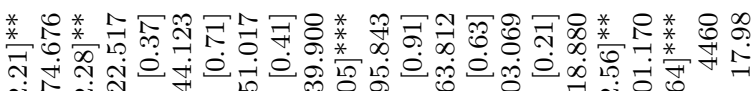

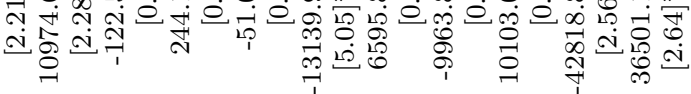

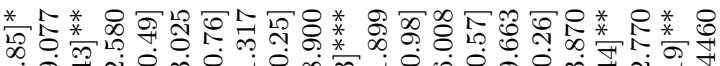

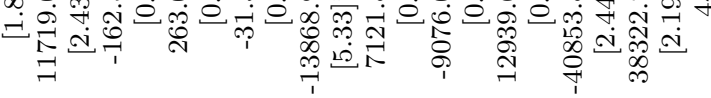

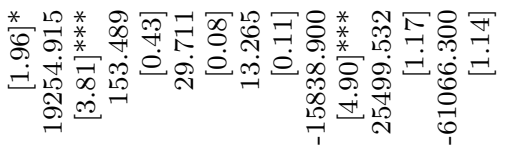

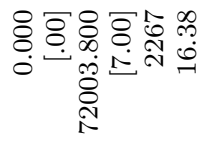

*

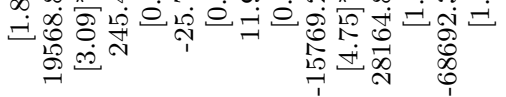

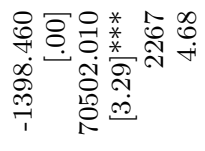

*

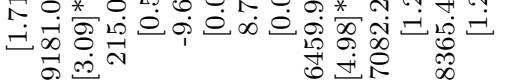

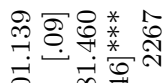

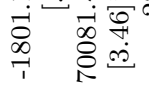

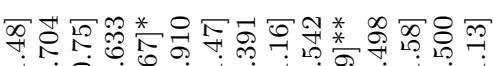

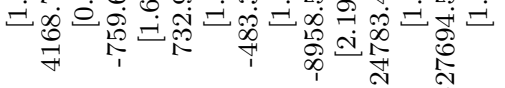

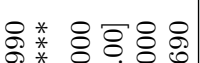

要过

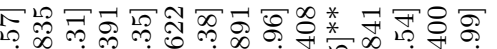

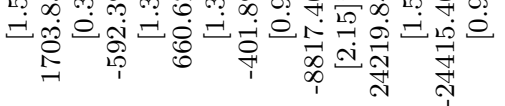

곤

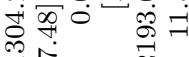

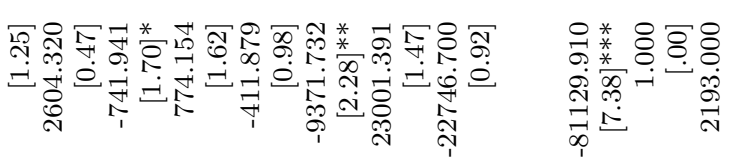

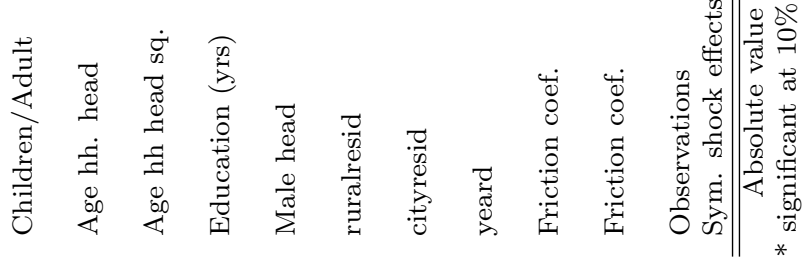


Table 11: Transfer derivatives implied by AI estimator: rural areas

\begin{tabular}{|c|c|c|c|c|c|c|}
\hline & (1) & (2) & (3) & (4) & (5) & (6) \\
\hline & \multicolumn{3}{|c|}{ Permanent income } & \multicolumn{3}{|c|}{ Transitory income } \\
\hline & $\frac{\partial T}{\partial I_{r}}$ & $\frac{\partial T}{\partial I_{d}}$ & $(2)-(3)$ & $\frac{\partial T}{\partial I_{r}}$ & $\frac{\partial T}{\partial I_{d}}$ & $(5)-(4)$ \\
\hline \multicolumn{7}{|l|}{1994} \\
\hline \multirow[t]{2}{*}{ Sample average } & -0.078 & 0.263 & 0.341 & -0.028 & 0.228 & 0.256 \\
\hline & {$[0.081]$} & {$[0.093]$} & {$[0.118]$} & {$[0.032]$} & {$[0.086]$} & [0.093] \\
\hline \multirow[t]{2}{*}{$1^{\text {st }}$ quartile } & -0.093 & 0.276 & 0.370 & -0.019 & 0.197 & 0.216 \\
\hline & {$[0.100]$} & {$[0.134]$} & {$[0.150]$} & {$[0.035]$} & {$[0.087]$} & {$[0.092]$} \\
\hline \multirow[t]{2}{*}{$2^{\text {nd }}$ quartile } & -0.071 & 0.235 & 0.306 & -0.027 & 0.267 & 0.294 \\
\hline & {$[0.090]$} & {$[0.094]$} & {$[0.124]$} & {$[0.034]$} & {$[0.082]$} & {$[0.090]$} \\
\hline \multirow[t]{2}{*}{$3^{\text {rd }}$ quartile } & -0.080 & 0.228 & 0.308 & -0.039 & 0.245 & 0.284 \\
\hline & {$[0.090]$} & {$[0.088]$} & {$[0.126]$} & {$[0.040]$} & {$[0.090]$} & {$[0.102]$} \\
\hline \multirow{2}{*}{$4^{t h}$ quartile } & -0.054 & 0.198 & 0.251 & -0.026 & 0.283 & 0.309 \\
\hline & {$[0.079]$} & {$[0.095]$} & {$[0.125]$} & {$[0.053]$} & {$[0.119]$} & [0.130] \\
\hline \multicolumn{7}{|l|}{1998} \\
\hline \multirow[t]{2}{*}{ Sample average } & -0.077 & 0.132 & 0.209 & -0.079 & 0.089 & 0.167 \\
\hline & {$[0.025]$} & {$[0.050]$} & {$[0.056]$} & {$[0.022]$} & {$[0.036]$} & {$[0.042]$} \\
\hline \multirow[t]{2}{*}{$1^{\text {st }}$ quartile } & -0.058 & 0.034 & 0.092 & -0.078 & 0.056 & 0.134 \\
\hline & {$[0.044]$} & {$[0.070]$} & {$[0.083]$} & {$[0.024]$} & {$[0.042]$} & {$[0.048]$} \\
\hline \multirow[t]{2}{*}{$2^{\text {nd }}$ quartile } & -0.090 & 0.112 & 0.202 & -0.085 & 0.058 & 0.143 \\
\hline & {$[0.031]$} & {$[0.051]$} & {$[0.060]$} & {$[0.023]$} & {$[0.034]$} & {$[0.042]$} \\
\hline \multirow[t]{2}{*}{$3^{\text {rd }}$ quartile } & -0.087 & 0.146 & 0.233 & -0.074 & 0.074 & 0.148 \\
\hline & {$[0.027]$} & {$[0.048]$} & {$[0.055]$} & {$[0.027]$} & {$[0.035]$} & {$[0.046]$} \\
\hline \multirow[t]{2}{*}{$4^{\text {th }}$ quartile } & -0.113 & 0.238 & 0.352 & -0.088 & 0.155 & 0.243 \\
\hline & {$[0.031]$} & {$[0.058]$} & {$[0.065]$} & {$[0.026]$} & {$[0.052]$} & {$[0.058]$} \\
\hline \multicolumn{7}{|l|}{1994 and 1998} \\
\hline \multirow[t]{2}{*}{ Sample average } & -0.051 & 0.137 & 0.188 & -0.060 & 0.168 & 0.228 \\
\hline & {$[0.020]$} & {$[0.033]$} & {$[0.041]$} & {$[0.028]$} & {$[0.048]$} & {$[0.057]$} \\
\hline \multirow[t]{2}{*}{$1^{\text {st }}$ quartile } & -0.039 & 0.124 & 0.163 & -0.056 & 0.155 & 0.211 \\
\hline & {$[0.032]$} & {$[0.048]$} & {$[0.059]$} & {$[0.029]$} & {$[0.051]$} & {$[0.061]$} \\
\hline \multirow[t]{2}{*}{$2^{\text {nd }}$ quartile } & -0.042 & 0.114 & 0.157 & -0.055 & 0.167 & 0.222 \\
\hline & {$[0.023]$} & {$[0.033]$} & {$[0.042]$} & {$[0.029]$} & {$[0.050]$} & {$[0.060]$} \\
\hline \multirow[t]{2}{*}{$3^{\text {rd }}$ quartile } & -0.061 & 0.111 & 0.171 & -0.067 & 0.161 & 0.227 \\
\hline & {$[0.022]$} & {$[0.030]$} & {$[0.040]$} & {$[0.030]$} & {$[0.047]$} & {$[0.058]$} \\
\hline \multirow[t]{2}{*}{$4^{\text {th }}$ quartile } & -0.079 & 0.143 & 0.222 & -0.074 & 0.189 & 0.263 \\
\hline & {$[0.026]$} & {$[0.036]$} & {$[0.046]$} & {$[0.034]$} & {$[0.051]$} & {$[0.062]$} \\
\hline
\end{tabular}

Standard errors are from bootstrap technique (500 simulations) are reported in brackets. 
Table 12: Transfer derivatives implied by AI estimator: urban areas

\begin{tabular}{|c|c|c|c|c|c|c|}
\hline & (1) & $(2)$ & $(3)$ & $(4)$ & $(5)$ & (6) \\
\hline & \multicolumn{3}{|c|}{ Permanent income } & \multicolumn{3}{|c|}{ Transitory income } \\
\hline & $\frac{\partial T}{\partial I_{r}}$ & $\frac{\partial T}{\partial I_{d}}$ & $(2)-(1)$ & $\frac{\partial T}{\partial I_{r}}$ & $\frac{\partial T}{\partial I_{d}}$ & $(5)-(4)$ \\
\hline \multicolumn{7}{|l|}{1994} \\
\hline \multirow[t]{2}{*}{ Sample average } & -0.0281 & 0.2201 & 0.2482 & -0.076 & 0.270 & 0.346 \\
\hline & {$[0.056]$} & {$[0.061]$} & {$[0.087]$} & {$[0.087]$} & {$[0.068]$} & {$[0.115]$} \\
\hline \multirow[t]{2}{*}{$1^{\text {st }}$ quartile } & -0.0448 & 0.2270 & 0.2718 & -0.018 & 0.154 & 0.173 \\
\hline & & {$[0.088]$} & {$[0.141]$} & {$[0.044]$} & {$[0.039]$} & {$[0.060]$} \\
\hline \multirow[t]{2}{*}{$2^{\text {nd }}$ quartile } & -0.0531 & 0.2108 & 0.2639 & -0.073 & 0.211 & 0.285 \\
\hline & {$[0.065]$} & {$[0.053]$} & {$[0.087]$} & {$[0.073]$} & {$[0.049]$} & {$[0.091]$} \\
\hline \multirow[t]{2}{*}{$3^{\text {rd }}$ quartile } & -0.0178 & 0.2389 & 0.2567 & -0.123 & 0.306 & 0.429 \\
\hline & & {$[0.052]$} & {$[0.077]$} & {$[0.129]$} & {$[0.073]$} & {$[0.152]$} \\
\hline \multirow[t]{2}{*}{$4^{t h}$ quartile } & 127 & 0.2254 & 0.2126 & -0.144 & 0.459 & 0.603 \\
\hline & & {$[0.077]$} & {$[0.099]$} & {$[0.168]$} & {$[0.123]$} & {$[0.220]$} \\
\hline \multicolumn{7}{|l|}{1998} \\
\hline \multirow[t]{2}{*}{ Sample average } & & 0.299 & 0.366 & -0.088 & 0.469 & 0.557 \\
\hline & & {$[0.039]$} & {$[0.051]$} & {$[0.080]$} & {$[0.070]$} & {$[0.107]$} \\
\hline \multirow[t]{2}{*}{$1^{\text {st }}$ quartile } & .074 & 0.227 & 0.301 & -0.050 & 0.352 & 0.402 \\
\hline & {$[0$.} & {$[0.055]$} & {$[0.083]$} & {$[0.043]$} & {$[0.056]$} & {$[0.071]$} \\
\hline \multirow[t]{2}{*}{$2^{\text {nd }}$ quartile } & -0.104 & 0.276 & 0.381 & -0.091 & 0.391 & 0.483 \\
\hline & {$[0.037]$} & {$[0.037]$} & {$[0.053]$} & {$[0.088]$} & {$[0.057]$} & {$[0.105]$} \\
\hline \multirow[t]{2}{*}{$3^{\text {rd }}$ quartile } & -0.069 & 0.276 & 0.345 & -0.113 & 0.460 & 0.574 \\
\hline & {$[0.037]$} & {$[0.031]$} & {$[0.049]$} & {$[0.108]$} & {$[0.072]$} & [0.128] \\
\hline \multirow[t]{2}{*}{$4^{t h}$ quartile } & 0.001 & 0.207 & 0.206 & -0.184 & 0.438 & 0.621 \\
\hline & {$[0.046]$} & {$[0.046]$} & {$[0.062]$} & {$[0.163]$} & {$[0.106]$} & {$[0.200]$} \\
\hline \multicolumn{7}{|l|}{1994 and 1998} \\
\hline \multirow[t]{2}{*}{ Sample average } & -0.021 & 0.287 & 0.308 & -0.083 & 0.341 & 0.425 \\
\hline & {$[0.023]$} & {$[0.029]$} & {$[0.036]$} & {$[0.043]$} & {$[0.044]$} & {$[0.065]$} \\
\hline \multirow[t]{2}{*}{$1^{\text {st }}$ quartile } & -0.041 & 0.189 & 0.230 & -0.048 & 0.239 & 0.287 \\
\hline & [0.043] & {$[0.038]$} & {$[0.055]$} & [0.023] & {$[0.029]$} & {$[0.040]$} \\
\hline \multirow[t]{2}{*}{$2^{\text {nd }}$ quartile } & -0.041 & 0.235 & 0.276 & -0.088 & 0.288 & 0.376 \\
\hline & {$[0.025]$} & {$[0.026]$} & {$[0.035]$} & {$[0.041]$} & {$[0.036]$} & {$[0.058]$} \\
\hline \multirow[t]{2}{*}{$3^{\text {rd }}$ quartile } & -0.015 & 0.277 & 0.292 & -0.114 & 0.357 & 0.471 \\
\hline & {$[0.021]$} & {$[0.028]$} & {$[0.033]$} & {$[0.062]$} & {$[0.045]$} & {$[0.080]$} \\
\hline \multirow[t]{2}{*}{$4^{t h}$ quartile } & 0.033 & 0.183 & 0.150 & -0.127 & 0.434 & 0.561 \\
\hline & {$[0.028]$} & {$[0.038]$} & {$[0.049]$} & {$[0.079]$} & {$[0.064]$} & {$[0.105]$} \\
\hline
\end{tabular}

Standard errors are from bootstrap technique (500 simulations) are reported in brackets. 


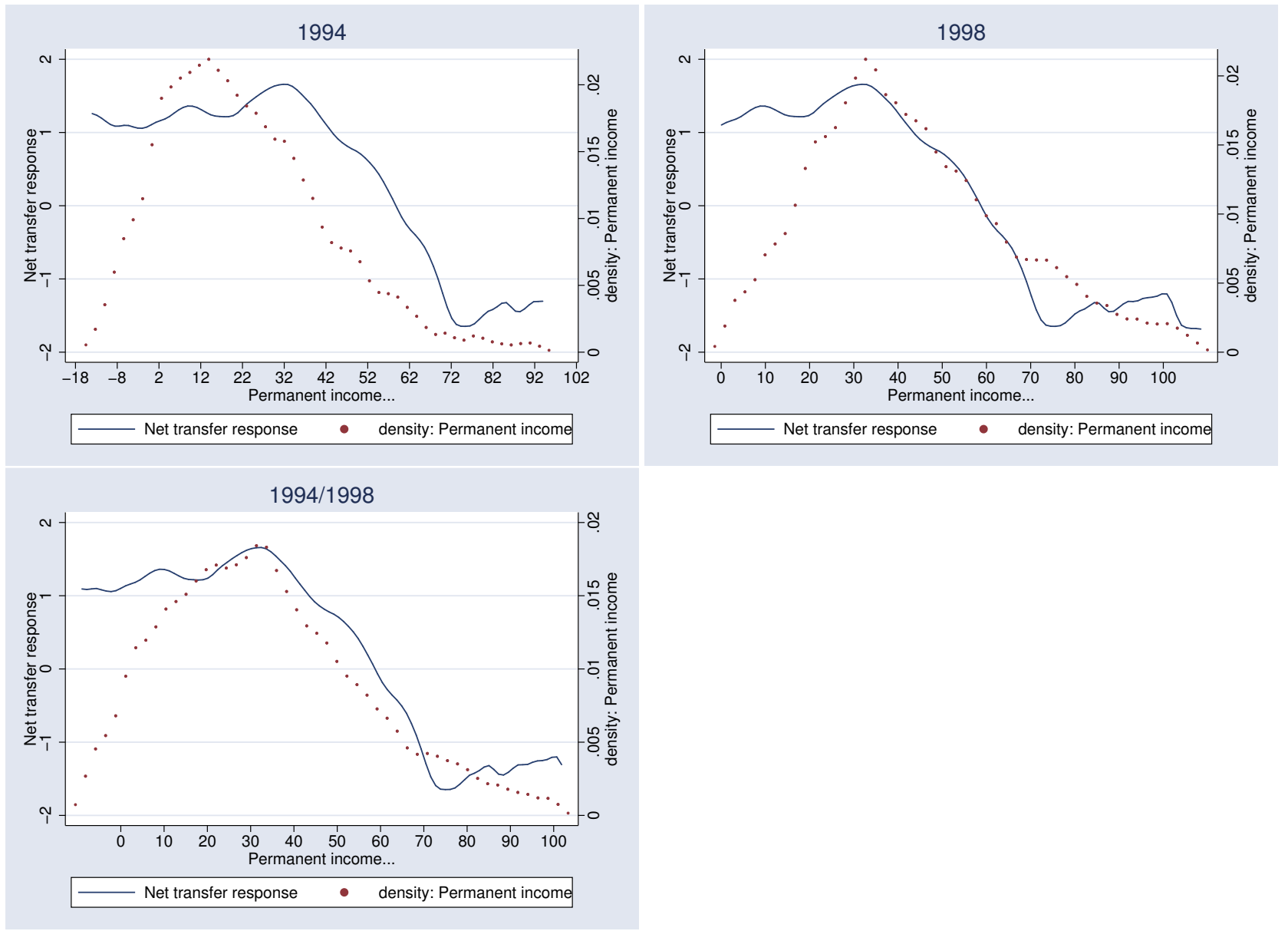

Figure 1: Transfer response to permanent income in rural areas 


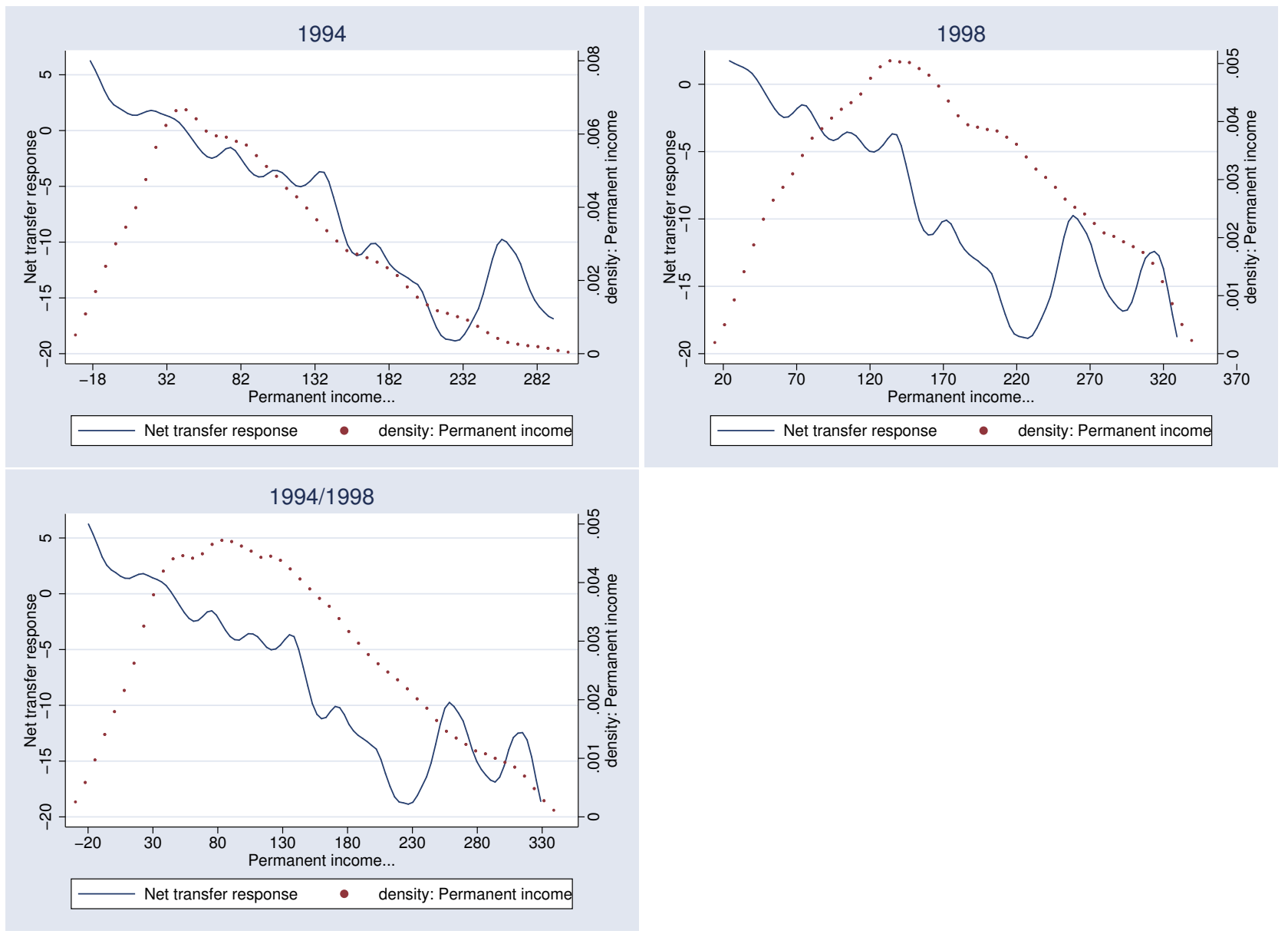

Figure 2: Transfer response to permanent income in urban areas 


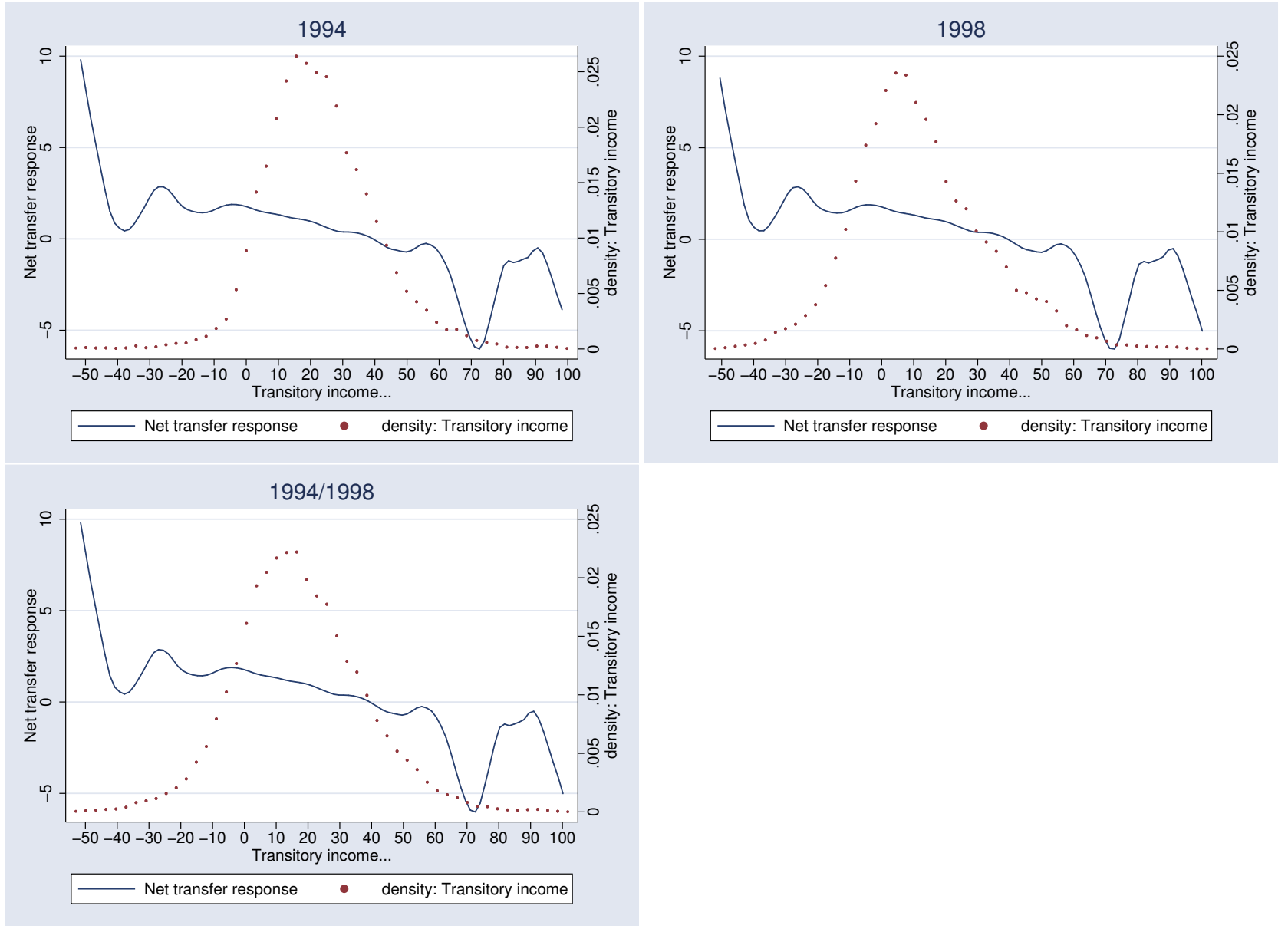

Figure 3: Transfer response to transitory income in rural areas 


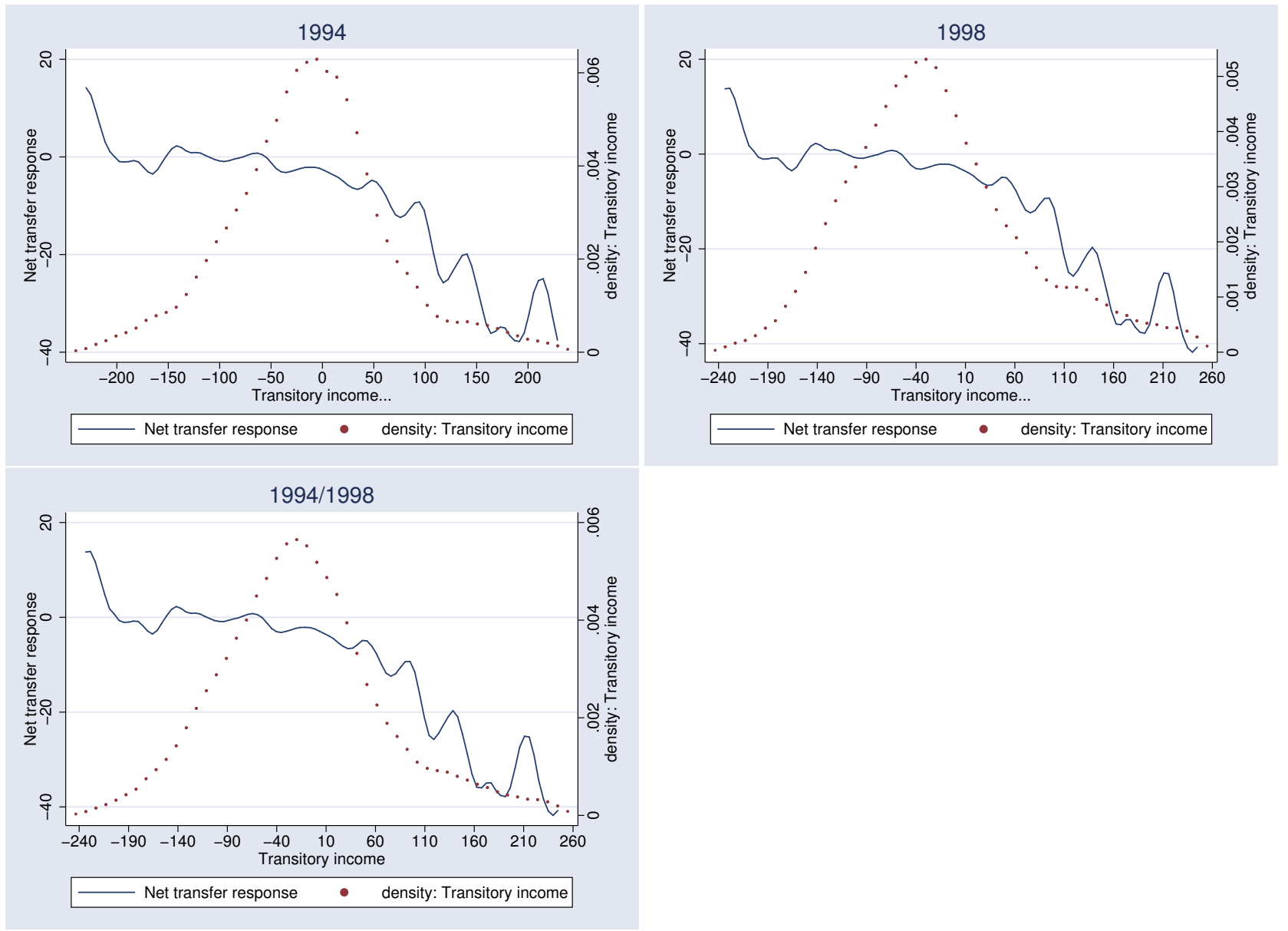

Figure 4: Transfer response to transitory income in urban areas 
Appendices

A descriptive statistics 
Table 13: Summary of variables used in estimations, rural sample

\begin{tabular}{|c|c|c|c|c|}
\hline & $(1)$ & $(2)$ & $(3)$ & $(4)$ \\
\hline variable & mean & st. deviation & $\min$ & $\overline{\max }$ \\
\hline \multicolumn{5}{|l|}{1994} \\
\hline Net transfers & 664.289 & 17476.780 & -444444.400 & 545454.600 \\
\hline Pre-transfer income & 40869.470 & 67068.610 & 1002.476 & 978154.800 \\
\hline boys, 6-11 & 0.128 & 0.152 & 0.000 & 1.000 \\
\hline girls, 6-11 & 0.112 & 0.143 & 0.000 & 1.500 \\
\hline boys, $12-15$ & 0.041 & 0.078 & 0.000 & 0.500 \\
\hline girls, $12-15$ & 0.039 & 0.079 & 0.000 & 1.000 \\
\hline men, 15-64 & 0.316 & 0.173 & 0.000 & 1.000 \\
\hline women, 15-64 & 0.350 & 0.162 & 0.000 & 1.000 \\
\hline men, older than 65 & 0.026 & 0.070 & 0.000 & 0.500 \\
\hline women, older than 65 & 0.021 & 0.075 & 0.000 & 1.000 \\
\hline children/adult & 0.519 & 0.458 & 0.000 & 4.000 \\
\hline age hh head & 47.927 & 15.063 & 15.000 & 99.000 \\
\hline education hh head & 0.357 & 1.449 & 0.000 & 15.000 \\
\hline hh head man & 0.956 & 0.205 & 0.000 & 1.000 \\
\hline household size & 7.230 & 4.684 & 1.000 & 39.900 \\
\hline cattle (number) & 2.387 & 6.398 & 0.000 & 90.000 \\
\hline sheep (number) & 3.377 & 6.179 & 0.000 & 94.000 \\
\hline goat (number) & 7.576 & 10.799 & 0.000 & 135.000 \\
\hline Farm equipment & 2.155 & 0.991 & 0.000 & 5.000 \\
\hline Other asset (dummy) & 0.029 & 0.169 & 0.000 & 1.000 \\
\hline ruralresid & 0.271 & 0.194 & 0.046 & 0.771 \\
\hline cityresid & 0.212 & 0.168 & 0.027 & 0.880 \\
\hline average rainfall $(\mathrm{mm})$ & 445.759 & 290.277 & 174.087 & 1607.861 \\
\hline rainfall deviation ( $\mathrm{mm}$ ) & -45.084 & 78.659 & -183.767 & 175.532 \\
\hline \multicolumn{5}{|l|}{1998} \\
\hline Net transfers & 797.842 & 16243.810 & -471993.300 & 213596.300 \\
\hline Pre-transfer income & 59140.700 & 65510.250 & 1146.695 & 704385.800 \\
\hline boys, $6-11$ & 0.125 & 0.148 & 0.000 & 1.000 \\
\hline girls, 6-11 & 0.121 & 0.147 & 0.000 & 2.000 \\
\hline boys, $12-15$ & 0.044 & 0.082 & 0.000 & 1.000 \\
\hline girls, $12-15$ & 0.041 & 0.084 & 0.000 & 1.000 \\
\hline men, 15-64 & 0.294 & 0.163 & 0.000 & 1.000 \\
\hline women, 15-64 & 0.358 & 0.163 & 0.000 & 1.000 \\
\hline men, older than 65 & 0.029 & 0.087 & 0.000 & 1.000 \\
\hline women, older than 65 & 0.029 & 0.100 & 0.000 & 1.000 \\
\hline children/adults & 0.530 & 0.477 & 0.000 & 5.000 \\
\hline age hh head & 48.149 & 15.050 & 15.000 & 99.000 \\
\hline education hh head & 0.340 & 1.485 & 0.000 & 15.000 \\
\hline hh head man & 0.945 & 0.228 & 0.000 & 1.000 \\
\hline household size & 6.517 & 3.993 & 1.000 & 30.500 \\
\hline cattle (number) & 3.790 & 11.073 & 0.000 & 250.000 \\
\hline sheep (number) & 4.405 & 7.517 & 0.000 & 100.000 \\
\hline goat (number) & 10.219 & 13.965 & 0.000 & 280.000 \\
\hline Farm equipment & 2.952 & 1.574 & 0.000 & 7.000 \\
\hline Other asset (dummy) & 0.366 & 0.510 & 0.000 & 2.000 \\
\hline ruralresid & 0.351 & 0.199 & 0.000 & 0.838 \\
\hline cityresid & 0.118 & 0.087 & 0.000 & 0.429 \\
\hline average rainfall (mm) & 626.232 & 368.984 & 164.400 & 1656.021 \\
\hline rainfall deviation $(\mathrm{mm})$ & -41.415 & 105.615 & -288.913 & 296.502 \\
\hline
\end{tabular}


Table 14: Summary of variables used in estimations, urban sample

\begin{tabular}{|c|c|c|c|c|}
\hline & (1) & $(2)$ & (3) & $(4)$ \\
\hline variable & mean & st. deviation & $\min$ & $\max$ \\
\hline Net transfers & -5173.160 & 25016.400 & -182222.200 & 78117.650 \\
\hline Pre-transfer income & 154407.300 & 156539.500 & 1026.106 & 990000.000 \\
\hline boys, $6-11$ & 0.096 & 0.143 & 0.000 & 1.000 \\
\hline girls, 6-11 & 0.097 & 0.137 & 0.000 & 0.800 \\
\hline boys, $12-15$ & 0.036 & 0.079 & 0.000 & 0.500 \\
\hline girls, $12-15$ & 0.042 & 0.087 & 0.000 & 1.000 \\
\hline men, 15-64 & 0.393 & 0.232 & 0.000 & 1.000 \\
\hline women, 15-64 & 0.337 & 0.188 & 0.000 & 1.000 \\
\hline men, older than 65 & 0.010 & 0.049 & 0.000 & 1.000 \\
\hline women, older than 65 & 0.013 & 0.052 & 0.000 & 0.500 \\
\hline children/adults & 0.451 & 0.473 & 0.000 & 3.000 \\
\hline age hh head & 41.369 & 12.625 & 15.000 & 99.000 \\
\hline education hh head & 3.305 & 4.538 & 0.000 & 15.000 \\
\hline hh head man & 0.903 & 0.296 & 0.000 & 1.000 \\
\hline househol size & 6.002 & 4.012 & 1.000 & 44.100 \\
\hline Senior position, formal sector & 0.065 & 0.246 & 0.000 & 1.000 \\
\hline Formal sectctor & 0.099 & 0.299 & 0.000 & 1.000 \\
\hline Skilled worke. & 0.079 & 0.270 & 0.000 & 1.000 \\
\hline unskilled worker & 0.114 & 0.318 & 0.000 & 1.000 \\
\hline casual worker & 0.082 & 0.274 & 0.000 & 1.000 \\
\hline self-employed & 0.475 & 0.499 & 0.000 & 1.000 \\
\hline undetermined & 0.086 & 0.280 & 0.000 & 1.000 \\
\hline pension recipient & 0.190 & 0.392 & 0.000 & 1.000 \\
\hline rent recipient & 0.018 & 0.134 & 0.000 & 1.000 \\
\hline refrigerator & 0.095 & 0.294 & 0.000 & 1.000 \\
\hline real estate & 0.174 & 0.379 & 0.000 & 1.000 \\
\hline motorcycle & 0.058 & 0.233 & 0.000 & 1.000 \\
\hline car & 0.215 & 0.411 & 0.000 & 1.000 \\
\hline ruralresid & 0.136 & 0.130 & 0.046 & 0.771 \\
\hline city & 0.165 & 0.098 & 0.027 & 0.417 \\
\hline \multicolumn{5}{|l|}{1998} \\
\hline Net transfers & -4386.514 & 23056.470 & -137983.200 & 73477.110 \\
\hline Pre-transfer income & 162575.700 & 156449.800 & 1025.262 & 973998.900 \\
\hline boys, $6-11$ & 0.084 & 0.140 & 0.000 & 1.000 \\
\hline girls, 6-11 & 0.083 & 0.140 & 0.000 & 1.000 \\
\hline boys, $12-15$ & 0.033 & 0.077 & 0.000 & 0.500 \\
\hline girls, $12-15$ & 0.033 & 0.078 & 0.000 & 0.500 \\
\hline men, 15-64 & 0.418 & 0.265 & 0.000 & 1.000 \\
\hline women, 15-64 & 0.346 & 0.214 & 0.000 & 1.000 \\
\hline men, older than 65 & 0.012 & 0.061 & 0.000 & 1.000 \\
\hline women, older than 65 & 0.015 & 0.076 & 0.000 & 1.000 \\
\hline children/adults & 0.374 & 0.449 & 0.000 & 4.000 \\
\hline age hh head & 42.369 & 13.478 & 16.000 & 99.000 \\
\hline education hh head & 3.997 & 4.984 & 0.000 & 15.000 \\
\hline hh head man & 0.869 & 0.338 & 0.000 & 1.000 \\
\hline household size & 4.678 & 3.138 & 1.000 & 24.000 \\
\hline Senior position, formal sector & 0.035 & 0.185 & 0.000 & 1.000 \\
\hline Formal sectctor & 0.090 & 0.287 & 0.000 & 1.000 \\
\hline Skilled worke. & 0.118 & 0.323 & 0.000 & 1.000 \\
\hline unskilled worker & 0.096 & 0.294 & 0.000 & 1.000 \\
\hline casual worker & 0.075 & 0.263 & 0.000 & 1.000 \\
\hline self-employed & 0.480 & 0.500 & 0.000 & 1.000 \\
\hline undetermined & 0.106 & 0.308 & 0.000 & 1.000 \\
\hline pension recipient & 0.151 & 0.358 & 0.000 & 1.000 \\
\hline rent recipient & 0.050 & 0.218 & 0.000 & 1.000 \\
\hline refrigerator & 0.120 & 0.325 & 0.000 & 1.000 \\
\hline real estate & 0.186 & 0.389 & 0.000 & 1.000 \\
\hline motorcycle & 0.480 & 0.500 & 0.000 & 1.000 \\
\hline car & 0.064 & 0.245 & 0.000 & 1.000 \\
\hline ruralresid & 0.266 & 0.181 & 0.076 & 0.838 \\
\hline city & 0.124 & 0.036 & 0.038 & 0.345 \\
\hline
\end{tabular}




\section{B First stage regression}

Table 15: First stage regression, rural sample

\begin{tabular}{|c|c|c|c|}
\hline & (1) & (2) & (3) \\
\hline \multirow{3}{*}{ Boys 6-11 } & 1994 & 1998 & $1994 / 98$ \\
\hline & -18894.600 & -17609.800 & -14677.100 \\
\hline & {$[2.88]^{* * *}$} & {$[2.41]^{* *}$} & {$[2.98]^{* * *}$} \\
\hline \multirow[t]{2}{*}{ Girls 6-11 } & -13480.000 & -5941.219 & -6716.702 \\
\hline & {$[1.96]^{*}$} & {$[0.81]$} & [1.33] \\
\hline \multirow[t]{2}{*}{ Boys 12-15 } & -21474.800 & 6441.373 & 97.978 \\
\hline & {$[1.74]^{*}$} & {$[0.53]$} & [0.01] \\
\hline \multirow[t]{2}{*}{ Girls $12-15$} & -12031.900 & 12773.249 & 2011.539 \\
\hline & {$[0.98]$} & {$[1.07]$} & {$[0.24]$} \\
\hline \multirow[t]{2}{*}{ Men 16-64 } & 47285.069 & 65789.594 & 64731.250 \\
\hline & {$[3.64]^{* * *}$} & {$[4.80]^{* * *}$} & {$[6.91]^{* * *}$} \\
\hline \multirow[t]{2}{*}{ Women 16-64 } & 4934.144 & 38153.513 & 34121.935 \\
\hline & {$[0.38]$} & {$[2.76]^{* * *}$} & {$[3.61]^{* * *}$} \\
\hline \multirow[t]{2}{*}{ Men $65+$} & 9424.535 & 55918.949 & 43064.457 \\
\hline & {$[0.54]$} & {$[3.23]^{* * *}$} & {$[3.56]^{* * *}$} \\
\hline \multirow{2}{*}{ Women $65+$} & -3455.826 & 30136.525 & 29666.267 \\
\hline & {$[0.24]$} & {$[1.79]^{*}$} & {$[2.70]^{* * *}$} \\
\hline \multirow[t]{2}{*}{ Children/Adult } & 8695.172 & 11470.084 & 12581.050 \\
\hline & {$[1.80]^{*}$} & {$[2.39]^{* *}$} & {$[3.75]^{* * *}$} \\
\hline \multirow[t]{2}{*}{ Age hh. head } & -802.597 & -1042.002 & -814.180 \\
\hline & {$[2.77]^{* * *}$} & {$[3.05]^{* * *}$} & {$[3.64]^{* * *}$} \\
\hline \multirow[t]{2}{*}{ Age hh head sq. } & 735.093 & 778.219 & 636.820 \\
\hline & {$[2.56]^{* *}$} & {$[2.30]^{* *}$} & {$[2.87]^{* * *}$} \\
\hline \multirow[t]{2}{*}{ Education (yrs) } & 1200.955 & 141.259 & 122.920 \\
\hline & {$[2.31]^{* *}$} & [1.12] & [1.10] \\
\hline \multirow[t]{2}{*}{ Male head } & -10202.900 & 3922.980 & -1712.458 \\
\hline & {$[2.38]^{* *}$} & {$[0.83]$} & {$[0.54]$} \\
\hline \multirow[t]{2}{*}{ hh size } & -1282.283 & -4173.902 & -2811.822 \\
\hline & {$[6.60]^{* * *}$} & {$[15.00]^{* * *}$} & {$[17.09]^{* * *}$} \\
\hline \multirow[t]{2}{*}{1998} & & & 27916.776 \\
\hline & & & {$[6.66]^{* * *}$} \\
\hline \multirow[t]{2}{*}{ Cattle } & 453.970 & 449.875 & 512.150 \\
\hline & {$[2.93]^{* * *}$} & {$[5.11]^{* * *}$} & {$[7.39]^{* * *}$} \\
\hline \multirow[t]{2}{*}{ Sheep } & 243.930 & 87.073 & 206.470 \\
\hline & {$[0.98]$} & {$[0.40]$} & [1.28] \\
\hline \multirow[t]{2}{*}{ Goat } & 107.865 & 216.768 & 110.743 \\
\hline & {$[0.72]$} & {$[1.83]^{*}$} & [1.22] \\
\hline \multirow[t]{2}{*}{ Other assets } & 5579.938 & -5694.647 & -2384.872 \\
\hline & {$[1.32]$} & {$[2.20]^{* *}$} & {$[1.22]$} \\
\hline \multirow[t]{2}{*}{ Farm asests } & 6733.652 & 11855.845 & 9047.499 \\
\hline & {$[7.24]^{* * *}$} & {$[12.67]^{* * *}$} & {$[13.62]^{* * *}$} \\
\hline \multirow[t]{2}{*}{ Rainfall deviation } & 426.055 & -122.082 & -28.873 \\
\hline & {$[2.47]^{* *}$} & {$[0.80]$} & {$[0.26]$} \\
\hline \multirow[t]{2}{*}{ Rainfall deviation sq. } & -20.051 & 27.452 & -5.968 \\
\hline & {$[2.27]^{* *}$} & {$[3.79]^{* * *}$} & {$[0.77]$} \\
\hline
\end{tabular}




\begin{tabular}{|c|c|c|c|}
\hline Millet & $\begin{array}{r}4367.568 \\
{[1.94]^{*}}\end{array}$ & $\begin{array}{r}-9355.549 \\
{[4.63]^{* * *}}\end{array}$ & $\begin{array}{r}2309.094 \\
{[1.48]}\end{array}$ \\
\hline Maize & -1787.499 & 12602.173 & 4532.535 \\
\hline & {$[1.05]$} & {$[6.35]^{* * *}$} & {$[3.19]^{* * *}$} \\
\hline Sorghum & -12515.700 & -1122.174 & -5071.398 \\
\hline & {$[6.10]^{* * *}$} & $\begin{array}{r}{[0.50]} \\
\end{array}$ & {$[3.18]^{* * *}$} \\
\hline Rice & 9686.277 & 12660.958 & 16476.746 \\
\hline & {$[4.63]^{* * *}$} & {$[5.61]^{* * *}$} & {$[10.20]^{* * *}$} \\
\hline Cowpea & 1767.465 & 451.147 & 231.693 \\
\hline & [1.00] & {$[0.24]$} & {$[0.17]$} \\
\hline Peanut & -411.426 & 3899.401 & 1206.435 \\
\hline & {$[0.23]$} & {$[2.05]^{* *}$} & {$[0.91]$} \\
\hline Cotton & 22283.318 & 29680.974 & 19168.354 \\
\hline & {$[8.46]^{* * *}$} & {$[12.45]^{* * *}$} & {$[10.01]^{* * *}$} \\
\hline Rainfall & deviation int & racted with & \\
\hline Boys 6-11 & -69.262 & -18.463 & -19.108 \\
\hline & [1.01] & {$[0.28]$} & {$[0.41]$} \\
\hline Girls 6-11 & -44.609 & -8.503 & 13.117 \\
\hline & {$[0.58]$} & {$[0.13]$} & {$[0.27]$} \\
\hline Boys $12-15$ & -261.186 & -170.423 & -132.829 \\
\hline & [1.96]* & {$[1.56]$} & [1.61] \\
\hline Girls $12-15$ & -243.603 & -71.120 & -114.578 \\
\hline & {$[1.86]^{*}$} & {$[0.65]$} & [1.39] \\
\hline Men 16-64 & -264.341 & 90.393 & 4.680 \\
\hline & {$[1.85]^{*}$} & {$[0.74]$} & {$[0.05]$} \\
\hline Women 16-64 & -407.711 & 14.082 & -84.331 \\
\hline & {$[2.86]^{* * *}$} & {$[0.11]$} & [0.92] \\
\hline Men $65+$ & -199.456 & 120.817 & 66.978 \\
\hline & [1.06] & {$[0.81]$} & [0.59] \\
\hline Women $65+$ & -411.519 & 15.234 & -66.118 \\
\hline & {$[2.51]^{* *}$} & {$[0.10]$} & {$[0.62]$} \\
\hline Children/Adult & -34.100 & 11.302 & 6.978 \\
\hline & [0.63] & {$[0.26]$} & {$[0.21]$} \\
\hline Age hh. head & -3.638 & 3.956 & 1.521 \\
\hline & {$[1.17]$} & {$[1.24]$} & {$[0.68]$} \\
\hline Age hh head sq. & 3.211 & -2.853 & -1.092 \\
\hline & {$[1.03]$} & {$[0.90]$} & {$[0.49]$} \\
\hline Education (yrs) & -0.930 & 0.831 & 0.498 \\
\hline & [0.18] & {$[0.68]$} & [0.46] \\
\hline Male head & -31.204 & 24.377 & 0.238 \\
\hline & [0.64] & {$[0.59]$} & {$[0.01]$} \\
\hline hh size & 11.917 & -8.771 & -0.916 \\
\hline & {$[5.09]^{* * *}$} & {$[3.38]^{* * *}$} & {$[0.52]$} \\
\hline Cattle & -6.878 & -0.715 & -1.626 \\
\hline & {$[3.77]^{* * *}$} & {$[0.93]$} & {$[2.50]^{* *}$} \\
\hline Sheep & -3.854 & 1.600 & -0.616 \\
\hline & {$[1.30]$} & {$[0.72]$} & {$[0.36]$} \\
\hline Goat & 0.570 & -1.788 & -1.199 \\
\hline & {$[0.32]$} & {$[1.40]$} & {$[1.20]$} \\
\hline Farm assets & -42.899 & 31.481 & 4.789 \\
\hline & {$[4.26]^{* * *}$} & {$[3.78]^{* * *}$} & {$[0.76]$} \\
\hline
\end{tabular}




\begin{tabular}{lrrr} 
Other assets & -15.999 & -2.361 & 39.343 \\
& {$[0.33]$} & {$[0.10]$} & {$[2.12]^{* *}$} \\
Millet & -97.495 & 11.838 & -15.472 \\
& {$[4.01]^{* * *}$} & {$[0.66]$} & {$[1.08]$} \\
Maize & 29.363 & 1.105 & 13.260 \\
& {$[1.56]$} & {$[0.06]$} & {$[1.01]$} \\
Sorghum & 10.783 & -16.159 & -7.486 \\
& {$[0.50]$} & {$[0.73]$} & {$[0.48]$} \\
Rice & 49.368 & 31.519 & 42.956 \\
& {$[2.23]^{* *}$} & {$[1.60]$} & {$[2.87]^{* * *}$} \\
Cowpea & 17.395 & 1.710 & -4.519 \\
& {$[0.94]$} & {$[0.11]$} & {$[0.37]$} \\
Peanut & -14.460 & 2.892 & -5.879 \\
& {$[0.76]$} & {$[0.17]$} & {$[0.48]$} \\
Cotton & -131.386 & -32.865 & -43.727 \\
& {$[4.69]^{* * *}$} & {$[1.49]$} & {$[2.41]^{* *}$} \\
Constant & 28905.516 & 36538.757 & -7603.468 \\
& {$[1.80]^{*}$} & {$[2.05]^{* *}$} & {$[0.55]$} \\
Observations & 4951 & 5470 & 10421 \\
R-squared & 0.22 & 0.21 & 0.26 \\
F test instruments & 19.30 & 25.83 & 24.96 \\
F test trans income & 19.30 & 25.83 & 24.96 \\
F test perm. income & 18.66 & 67.66 & 21.33 \\
\hline \hline \multicolumn{2}{c}{ Absolute value of $t$ statistics in brackets }
\end{tabular}

Absolute value of t statistics in brackets
significant at 10\%; ** significant at 5\%; *** significant at $1 \%$ Regression includes also province dummies for 1998. 
Table 16: First stage regression, urban sample

\begin{tabular}{|c|c|c|c|}
\hline & (1) & (2) & (3) \\
\hline & 1994 & 1998 & $1994 / 98$ \\
\hline \multirow{2}{*}{ Boys 6-11 } & -50597.600 & -23309.600 & -41510.500 \\
\hline & {$[1.97]^{* *}$} & {$[0.99]$} & {$[2.37]^{* *}$} \\
\hline \multirow[t]{2}{*}{ Girls 6-11 } & -27622.700 & -44787.000 & -42251.400 \\
\hline & [1.03] & {$[1.95]^{*}$} & {$[2.39]^{* *}$} \\
\hline \multirow[t]{2}{*}{ Boys 12-15 } & -47449.900 & -66222.100 & -60121.300 \\
\hline & {$[1.10]$} & {$[1.61]$} & {$[2.00]^{* *}$} \\
\hline \multirow[t]{2}{*}{ Girls $12-15$} & -22239.900 & -80855.500 & -53978.300 \\
\hline & {$[0.56]$} & {$[2.04]^{* *}$} & {$[1.91]^{*}$} \\
\hline \multirow[t]{2}{*}{ Men 16-64 } & 303287.000 & 217443.000 & 261814.000 \\
\hline & {$[6.37]^{* * *}$} & {$[4.98]^{* * *}$} & {$[8.08]^{* * *}$} \\
\hline \multirow[t]{2}{*}{ Women 16-64 } & 186590.000 & 94593.413 & 138020.000 \\
\hline & {$[3.82]^{* * *}$} & {$[2.12]^{* *}$} & {$[4.16]^{* * *}$} \\
\hline \multirow[t]{2}{*}{ Men 65 + } & 251598.000 & 181930.000 & 215657.000 \\
\hline & {$[3.23]^{* * *}$} & {$[2.86]^{* * *}$} & {$[4.35]^{* * *}$} \\
\hline \multirow{2}{*}{ Women 65 + } & 195061.000 & 31914.821 & 105775.000 \\
\hline & {$[2.72]^{* * *}$} & {$[0.56]$} & {$[2.40]^{* *}$} \\
\hline \multirow[t]{2}{*}{ Children/Adult } & 58569.975 & 48404.034 & 53919.953 \\
\hline & {$[3.27]^{* * *}$} & {$[2.80]^{* * *}$} & {$[4.31]^{* * *}$} \\
\hline \multirow[t]{2}{*}{ Age hh. head } & -2070.476 & -2875.873 & -2659.177 \\
\hline & [1.57] & {$[2.46]^{* *}$} & {$[3.02]^{* * *}$} \\
\hline \multirow[t]{2}{*}{ Age hh head sq. } & 1085.444 & 2214.325 & 1650.950 \\
\hline & {$[0.78]$} & {$[1.81]^{*}$} & [1.78]* \\
\hline \multirow[t]{2}{*}{ Education (yrs) } & 6358.199 & 859.116 & 1687.517 \\
\hline & {$[7.31]^{* * *}$} & {$[2.70]^{* * *}$} & {$[5.50]^{* * *}$} \\
\hline \multirow[t]{2}{*}{ Male head } & -17808.200 & -30674.600 & -25692.200 \\
\hline & {$[1.73]^{*}$} & {$[3.46]^{* * *}$} & {$[3.79]^{* * *}$} \\
\hline \multirow[t]{2}{*}{ yeard } & & & -51472.100 \\
\hline & & & {$[0.42]$} \\
\hline \multirow[t]{2}{*}{ Refrigerator } & 53172.633 & -7377.562 & 38115.278 \\
\hline & {$[4.49]^{* * *}$} & {$[0.61]$} & {$[4.70]^{* * *}$} \\
\hline \multirow[t]{2}{*}{ Real estate } & 23236.571 & -2045.379 & 12262.875 \\
\hline & {$[3.12]^{* * *}$} & {$[0.30]$} & {$[2.42]^{* *}$} \\
\hline \multirow{2}{*}{ Motor cycle } & 57525.633 & 34428.358 & 44573.690 \\
\hline & {$[4.25]^{* * *}$} & {$[5.59]^{* * *}$} & {$[8.19]^{* * *}$} \\
\hline \multirow[t]{2}{*}{ Car } & 42764.637 & 117629.000 & 64241.905 \\
\hline & {$[4.89]^{* * *}$} & {$[8.48]^{* * *}$} & {$[9.49]^{* * *}$} \\
\hline \multirow[t]{2}{*}{ Other Assets } & 4508.479 & -12017.500 & -5268.478 \\
\hline & {$[0.46]$} & {$[1.26]$} & {$[0.78]$} \\
\hline \multirow[t]{2}{*}{ Formal sect. } & -2050.006 & -35544.100 & -11982.300 \\
\hline & {$[0.14]$} & {$[2.22]^{* *}$} & [1.15] \\
\hline \multirow[t]{2}{*}{ Skilled emp. } & -20203.200 & -107086.000 & -64511.700 \\
\hline & {$[1.34]$} & {$[6.57]^{* * *}$} & {$[6.00]^{* * *}$} \\
\hline \multirow[t]{2}{*}{ Unskilled emp. } & -33945.000 & -131081.000 & -84776.400 \\
\hline & {$[2.35]^{* *}$} & {$[7.65]^{* * *}$} & {$[7.79]^{* * *}$} \\
\hline \multirow[t]{2}{*}{ Casual worker } & -64697.000 & -126436.000 & -99525.400 \\
\hline & {$[4.16]^{* * *}$} & {$[7.10]^{* * *}$} & {$[8.63]^{* * *}$} \\
\hline
\end{tabular}




\begin{tabular}{lrrr} 
Independent & -35852.900 & -132322.000 & -88113.300 \\
& {$[2.72]^{* * *}$} & {$[8.42]^{* * *}$} & {$[8.95]^{* * *}$} \\
Undetermined & -67548.200 & -162932.000 & -115850.000 \\
& {$[4.32]^{* * *}$} & {$[9.38]^{* * *}$} & {$[10.18]^{* * *}$} \\
Pension recipient & 6023.627 & 8633.044 & 5287.155 \\
& {$[0.82]$} & {$[1.11]$} & {$[1.00]$} \\
Rent recipient & 6060.064 & 21226.900 & 11613.836 \\
& {$[0.30]$} & {$[1.78]^{*}$} & {$[1.12]$} \\
Constant & 40123.955 & 230770.000 & 161222.000 \\
& {$[0.55]$} & {$[3.82]^{* * *}$} & {$[3.44]^{* * *}$} \\
Observations & 2143 & 2278 & 4421 \\
R-squared & 0.39 & 0.45 & 0.40 \\
F test instruments & 12.01 & 34.23 & 42.00 \\
\hline \hline
\end{tabular}

Absolute value of t statistics in brackets

* significant at $10 \%$; $*$ significant at $5 \%$; ${ }^{* * *}$ significant at $1 \%$

Regression includes also province dummies. 